\title{
Analyzing driving forces of China's carbon emissions from 1997 to 2040 and the potential emission reduction path: through decomposition and scenario analysis
}

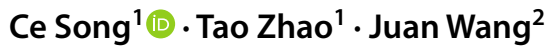 \\ Received: 25 May 2021 / Accepted: 11 November 2021 / Published online: 26 November 2021 \\ (c) The Author(s), under exclusive licence to Springer-Verlag GmbH Germany, part of Springer Nature 2021
}

\begin{abstract}
Energy and environmental policies are important methods for the government to restrain carbon emissions growth. Identifying the potential dynamic trends of China's carbon emissions under different scenarios has important reference significance for the government's policy implementation. This paper firstly predicted China's carbon emissions from 2017 to 2040 based on three energy transition scenarios at the industrial level. Then, Logarithmic Mean Divisia Index decomposition model was applied to evaluate the driving forces of emissions changes during 1997-2040. Finally, the Spatial-Temporal Logarithmic Mean Divisia Index model was used to explore the emissions reduction potential and the potential reduction path at provincial level. The results showed that (1) as the reduction in energy intensity cannot offset the growth of industrial scale, the carbon emissions of all industries have shown an increasing trend from 1997 to 2017; (2) In the current policies scenario, China's carbon emissions cannot reach the peak before 2040. And only in the sustainable development scenario, the carbon emissions of the three industries will all reach the peaks before 2030. And the development of non-fossil energy will reduce carbon emissions by more than 30\%; (3) Hebei, Shanxi, Inner Mongolia, Ningxia, and Heilongjiang are key provinces and improving energy efficiency of the secondary industry is a potential way to promote carbon emissions reduction.
\end{abstract}

Ce Song

ce_song@tju.edu.cn

1 School of Economics and Management, Tianjin University, Tianjin 300072, People's Republic of China

2 College of Finance, Tianjin University of Finance and Economics, Tianjin 300222, People's Republic of China 


\section{Graphical abstract}

The framework and main content of this paper.

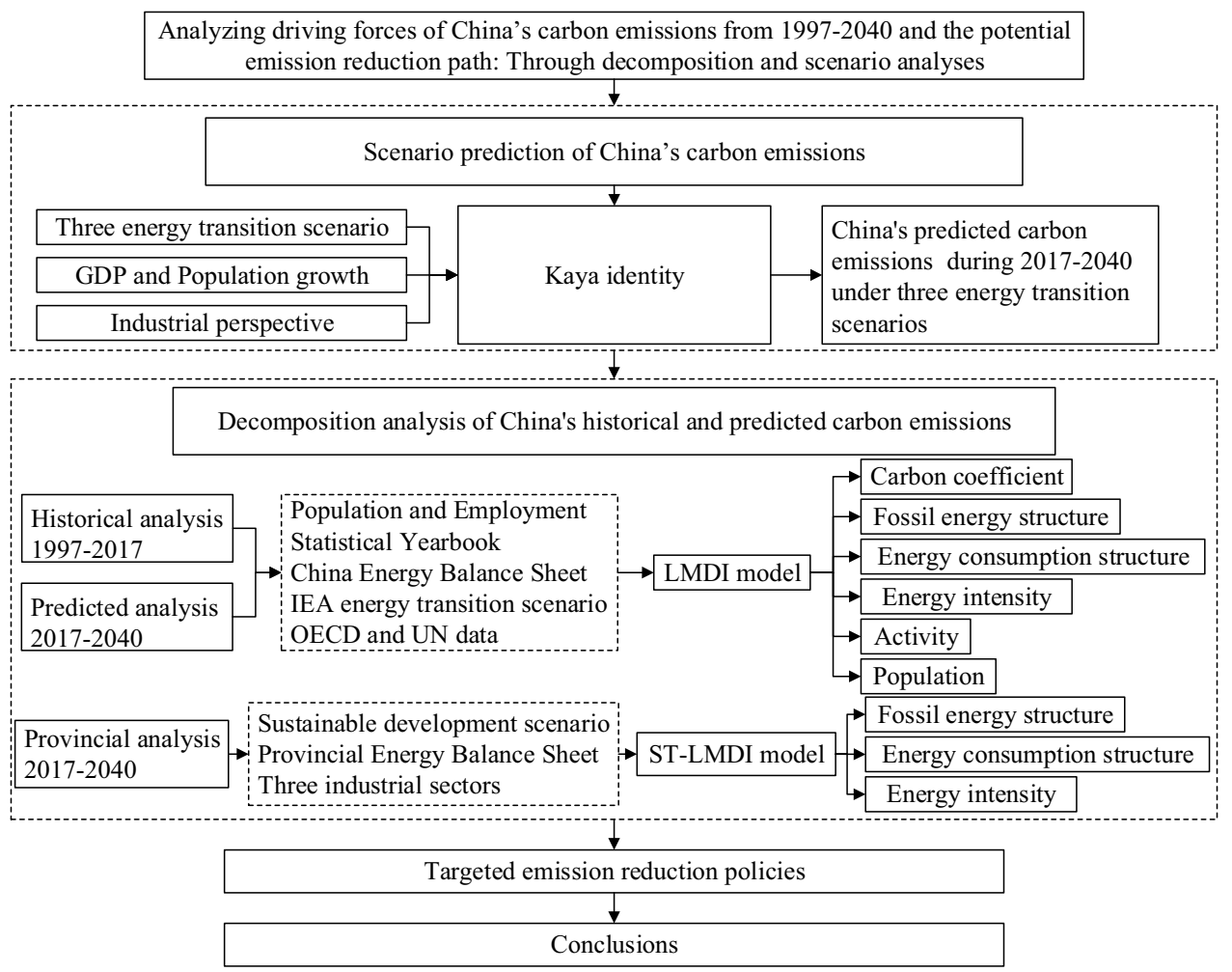

Keywords Carbon emissions $\cdot$ Decomposition model $\cdot$ Scenario analysis $\cdot$ Provincial analysis

\section{Introduction}

As human activities promote global economic growth, related energy consumption has led to a continuous increase in carbon emissions (CEs) (Ikram et al. 2021). The increase in global CEs has caused serious damage to the environment and biodiversity (Sharma et al. 2021). The United Nations (UN) has put forward the Sustainable Development Goals (SDGs), aiming to solve the development problems of the three dimensions of society, economy, and environment in an integrated manner and turn to the path of sustainable development (UN 2015). In a series of SDGs, clean energy and climate action are of great significance to the sustainable development of human society (Malik et al. 2021). It requires governments to take urgent action to deal with climate change and its impact, and to develop clean energy to ensure global energy supply (Ghazouani et al. 2021). However, recognition to action requires a transition process. This requires policymakers to consider various practical factors to formulate reasonable and effective policies. Therefore, studying energy and environmental policies are of great significance to promoting energy transition, curbing the growth of CEs, and realizing SDGs.

China's economy has grown rapidly in recent decades (Jiang et al. 2018). However it also brings serious environmental problems. In 2009, China surpassed USA to become the world's largest carbon emitter (Wang et al. 2010). In 2017, total CEs in China were 9866Mtons, accounting for $30.05 \%$ of the global total (IEA 2018). Resources and environmental problems have brought huge potential threatens to the sustainable development of China (Liu et al. 2018). Due to the process of industrialization and urbanization, China's air pollution problem has gradually increased, and public health has been seriously threatened (Tian et al. 2013). For example, starting in 2013, from November to January of the following year, severe smog frequently occurred in North China, and the health of more than 300 million people was seriously threatened (Bing et al. 2014). Considering the cobenefits between air pollution and CEs, to reverse the current air quality situation in China, it is essential to control fossil energy consumption and reduce CEs (Dong et al. 2015). Therefore, the Chinese government has issued a series of policies aimed at energy consumption transformation and 
industrial structure optimization in an attempt to control the fossil fuel consumption and related CEs (Deng et al. 2019). In 2016, the State Council promulgated the "13th 5-Year Plan," requiring China to decrease the carbon intensity (CI) by $18 \%$ in 2020 compared to 2015 (NDRC 2017). In 2017, the Chinese government promulgated the National Independent Contribution Program (INDC), promising to reduce CI by $60-65 \%$ from the 2005 level, and peaked China's CEs in 2030 (Yuan et al. 2018). In 2021, according to the 14th 5-Year Plan, China pledged to achieve carbon neutrality by 2060 (NDRC 2021).

The implementation of a series of emission reduction policies has had a certain effect on restraining the growth of CEs of China (Ding et al. 2019). From 2013 to 2017, China's CEs increased from 9492.9 to 9866 Mtons, with an average annual growth rate of $0.98 \%$, which was much lower than the $7.61 \%$ during 1997-2013 (NBSC 1998-2018b). However, these are far from enough for carbon peaking and carbon neutrality goals. At the current stage, the Chinese government has only proposed some binding indicators for these goals, and the specific policies and action plans are still unclear. This raised some questions: What are the characteristics of China's CEs at different stages? How will China's CE change under different emission reduction policies? What are the main drivers for the dynamics of CEs? To achieve the carbon emission reduction target, what kind of policies are practical and effective? In addition, China has a huge territory. The industrial structure and resource endowments vary greatly among provinces. There are serious inequalities in CEs among provinces. In 2017, the five provinces with the largest CEs were Shandong (806Mtons), Jiangsu (736Mtons), Hebei (726Mtons), Inner Mongolia (639Mtons), and Guangdong (542Mtons), accounting for $34.96 \%$ of the national total. On the contrary, the five provinces with the least CEs were Hainan (42Mtons), Qinghai (53Mtons), Beijing (85Mtons), Tianjin (141Mtons), and Gansu (151Mtons), accounting for only $4.78 \%$ of the national total. Considering that CEs reduction targets are closely related to each province, evaluating the driving factors of provincial CEs changes and identifying potential ways to reduce CEs in each province is of great significance for achieving China's CEs reduction targets.

To solve the above problems, this paper first analyzed the evaluation trends and driving forces of China's CEs during 1997-2017. Then, three energy demand scenarios were constructed to estimate the evolution trend of China's CEs in different scenarios during 2017-2040, and assessed the potential impact of the energy transition on CEs. Furthermore, Logarithmic Mean Divisia Index (LMDI) method was used to assess the main driving forces for the dynamics of China's CEs during 2017-2040. Finally, the Spatial-Temporal Logarithmic Mean Divisia Index (ST-LMDI) model was used to evaluate the CEs reduction potential of each province in different scenarios. In particular, this paper analyzed the relative contribution of the proportion of fossil energy in total energy consumption to CEs to indirectly illustrate the effect of non-fossil energy consumption on CEs changes. As this paper covered main types of primary energy sources including fossil and non-fossil energy, impacts of technological progress and non-fossil energy substitution can be presented. This supplemented more detailed information for assessing the potential for future CEs reduction, and provided new evidences for relevant government departments to make decisions.

The reminder of this paper was as follows. Section Literature review presents an overview of existing relevant research. Section Methodology and data introduces Kaya identities, Scenario analysis, decomposition analysis and the data sources. Section Results provides the results. And Sect. Policy recommendations concludes the research and gives the policy recommendations.

\section{Literature review}

Many scholars have explored the co-benefits of air pollution and CEs. The early studies mainly focused on developed countries (Rafaj et al. 2013; Shrestha and Pradhan 2010). However, the air pollution and CEs problems faced by developing countries are more serious, and the pursuit of co-benefits is even more urgent (Takeshita 2012). He et al. (2010) combined energy prediction models, emission estimation models, air quality simulation models, and health benefit evaluation models to evaluate the co-benefits of different energy policies. Mao et al. (2012) studied the co-benefits of carbon dioxide emission reduction and air pollutants in China's transportation sector based on policy tools such as carbon tax and clean energy subsidies. Liu et al. (2013) applied the GAINS-City model to analyze the synergistic effect of Beijing's air pollution and CEs. These studies have confirmed that energy and environmental policies have significant co-benefits for air quality and CEs. Implementing proactive energy and environmental policies can not only curb the growth of CEs, but also promote air quality improvement.

Therefore, an increasing number of researchers focused on the issue of China's CEs through different kinds of models such as decomposition (IDA and SDA) model (Wang and Zhou 2018), STIRPAT model (Zhang and Zhao 2019), decoupling indicator (Wang et al. 2018b), and regression analysis (Wen and Liu 2016). Wang et al. (2021a) applied a decomposition analysis model based on World-Input-Output Database to explore the key drivers of changes in $\mathrm{CI}$ in 55 sectors in China, aiming to curb the possible rebound in CI after the COVID-19 pandemic. Wang et al. (2021b) conducted a study on CEs from the perspective of energy 
demand, and found that structural changes in energy consumption have a significant impact on CEs. Guo et al. (2021) studied the impact of clean energy development on provincial CEs and found that clean energy is a viable solution to alleviate China's environmental degradation. Fatima et al. (2021) studied the relationship between energy transition and the environment and found that the development of nonfossil energy can significantly inhibit the negative impact of economic growth on the environment. These studies confirmed that the energy transition especially the development of non-fossil energy will have a significant impact on CEs. Therefore, exploring the trends of CEs under different energy transition scenarios can provide an important reference for the government and is of great significance for policy making.

Logarithmic Mean Divisia Index (LMDI) model was used by many scholars to identify the impact factors of CEs (Liu et al. 2019). Compared with other decomposition analysis methods, the LMDI method mainly used final consumption data and relied on the Kaya identity to decompose changes in CEs into factors such as intensity, structure, economy, and population (Du and Lin 2015). The LMDI method has low data requirements and a wide range of applications, and has been widely used by many scholars. Xu et al. (2014) analyzed influencing factor of China's CEs. The results showed that economic activity was the major force for the growth of CEs. Li et al. (2017b) explored the drivers of China's growth of CEs. Results showed that energy intensity was the dominant driver to restrain the growth of CEs. Previous studies have fully demonstrated that economic activity and energy intensity are the main driving forces in promoting and curbing China's growth of CEs. Furthermore, an increasing number of scholars have shifted their focus to CEs at the regional level. Song et al. (2021) studied the dynamics of China's provincial CEs and found that the CEs center shifted from east to west China during 2000-2017. Wang and Feng (2017) explored the drivers of CEs changes at China's provincial level and found that the influencing factors vary greatly among different provinces. Jiang et al. (2017) analyzed the differences in the impact factors of CEs growth of various provinces, and found that Shanxi, Anhui, and Hebei have made increased contributions on China's growth of CEs. Wang and Han (2021) used multi-regional input-output (MRIO), Tapio decoupling model and decomposition analysis to study the decoupling of CEs in Sino-US trade and its driving factors, and found that the decoupling status of CEs reflected in China's exports to USA is gradually improved. Wang and Wang (2020) applied the LMDI model to explore the driving factors of CEs in various countries before and after the 2008 global financial crisis, and discussed specific measures to prevent the retaliatory growth of CEs after COVID-19.
These studies have conducted extensive discussions on historical CEs changes. However, there is limited researches on the potential evaluation trends and driving factors of future CEs. Zhang et al. (2019) assessed the influencing forces affecting growth of CEs in China during 2000-2016, and estimated the decline trend in CI in 2020 and 2030. It was found that energy intensity was the leading factor for CEs reduction, and industrial structure optimization would have an important impact on 2020-2030 CEs reduction. Sun et al. (2019) found that benefiting from non-fossil energy consumption, China's CI can be reduced by up to $72.7 \%$ in 2030 compared to 2005. Some studies have predicted the CEs of a single province in China. Zhang et al. (2017) predicted that future emission pattern of Henan province will show an increasing initially and follows by a downward trend, which mainly depended on the population growth rate and changes in per capita GDP. Wang et al. (2019) found that based on the continuous economic development and urbanization process, CEs in Guangdong will maintain a growth trend in 2015-2030. Qin et al. (2019) predicted the changes of CEs in Xinjiang and found that its CEs will peak at 626.21-662.25Mtons in 2030-2040. Yu et al. (2019) predicted the CEs reduction in the Beijing-Tianjin-Hebei region up to 2030, and found that energy intensity is the key driver for achieving CEs reduction targets. Wang et al. (2018a) predicted the CI of six provinces of Southeast coast of China, and found that by 2030 , the CI of these provinces will be reduced by $59.1-69.7 \%$ compared to 2005 .

Existing research is insufficient in predicting China's subsectoral CEs and CI, and analyzing the CEs reduction potential at the provincial level. In limited research, Zhang et al. (2020) estimated the dynamic trends of CEs in 30 provinces up to 2030, and found that most provinces can achieve the CEs reduction target. Sun et al. (2019) estimated that China's CI can be reduced by up to $72.7 \%$ in 2030 compared to 2005 , and Hebei, Shandong, Shanxi, Liaoning, Xinjiang, and Inner Mongolia were the key provinces. Besides, existing studies ignore the impact of different energy transition policies on CEs at industrial perspective. Given that the energy transition, especially the development of non-fossil energy, can significantly inhibit the growth of CEs, assessing the trend of changes in CEs under different energy transition scenarios has an important reference value for the government to formulate energy policies. Therefore, this paper applied Kaya identities to predict China's potential CEs of three subsectors during 2017-2040 based on three different energy transition policies, evaluated the impact of energy transition on China's CEs dynamic trend. Besides, this paper also applied ST-LMDI model to analyze the spatial and temporal differences of CEs between each provinces and predicted scenario, and evaluated the influencing factors of CEs reduction in each province. 
This paper contributes the literature as follows. First, this paper combined the scenarios of IEA and OECD to predict the trend of China's CEs during 2017-2040 based on Kaya identity, and explored the potential impact of the energy transition, especially the impact of non-fossil energy on CEs. With the support of the government, China has developed rapidly in the field of non-fossil energy. By 2030, China's non-fossil energy power generation installed capacity is expected to account for more than 50\%, and non-fossil energy power generation will account for more than $30 \%$. This will have an important impact on China's CEs, and it is of great significance to study the impact of energy transition on China's CEs. Besides, previous studies have mainly emphasized the inter-industry differences in historical CEs. Few studies have predicted China's CEs by sectors. Then, this paper applied LMDI method to evaluate the drivers of China's CEs in different scenarios from 2017 to 2040. Finally, ST-LMDI model was applied to analyze the spatial and temporal differences of CEs between each provinces and predicted scenario. This will help to explore the potential path for CEs reduction in provincial level, and provide important references for the governments to formulate emission reduction policies.

\section{Methodology and data}

\section{Kaya identities}

Kaya identities has been widely applied in the study related to CEs drivers. This paper utilized different Kaya identities to study CEs at both national and provincial levels respectively. At national level, CEs was decomposed into six influencing factors including the carbon coefficient, fossil energy structure, energy consumption structure, energy intensity, activity, and population. At provincial level, to eliminate the influence of geographic factors, this paper chose CI as the research object. CI was decomposed into four drivers including carbon coefficient, fossil energy structure, energy consumption structure, and energy intensity. consumption; ES means fossil energy structure, represented by the proportion of fuel coal, oil, and gas consumption in fossil energy consumption respectively; $T$ means energy consumption structure, represented by the proportion of fossil energy consumption in total energy consumption; EI means energy intensity, represented by energy consumption GDP per capita; $A$ means activity, represented by economic output; $P$ means population, represented by the number of employed population.

\section{Scenario analysis}

Prediction research is forward-looking for evaluating future development trends, and has been favored by many scholars. Wang and Zhang (2021) predicted the impact of China's economic recovery after the COVID-19 pandemic on the economic growth and energy consumption of other countries. Scenario analysis is a commonly used multi-factor forecasting method. Based on multi-scenario assumptions, it studies the possible results of a combination of multiple factors. Predicting the dynamic trend of CEs is of great significance for assessing the potential impact of economic development on CEs, predicting the negative environmental effects of human activities, and proposing forward-looking policies to prevent risks caused by the greenhouse effect. In recent years, environmental issues have gradually received widespread attention, many scholars predicted the future trend of CEs through scenario analysis. Cui et al. (2021) applied scenario analysis to predict the $\mathrm{CI}$ of five urban agglomerations in China in 2025. Zhu et al. (2020) estimated the peak of CEs in China's transportation sector under three scenarios. Niu et al. (2020) evaluates China's CI in 2030 under different scenarios and finds that under the BAU scenario, China cannot meet its 2030 CEs reduction commitments. However, the existing scenario analysis is mainly based on the growth rate of various socioeconomic indicators, ignoring the difference between industries and the impact of non-fossil energy. According to the scenario analysis method, this study forecasted the CEs of China's three industries and related influ-

$$
\begin{aligned}
& \mathrm{CE}=\sum_{i} \mathrm{CE}_{i}=\sum_{i} \sum_{n} \frac{\mathrm{CE}_{n i}}{F_{n i}} \times \frac{F_{n i}}{F_{i}} \times \frac{F_{i}}{E_{i}} \times \frac{E_{i}}{Q_{i}} \times \frac{Q_{i}}{P_{i}} \times P_{i}=\sum_{i} \sum_{n} \mathrm{CF}_{n i} \times \mathrm{ES}_{n i} \times T_{i} \times \mathrm{EI}_{i} \times A_{i} \times P_{i} \\
& \mathrm{CI}_{j}=\frac{\mathrm{CE}_{j}}{Q_{j}}=\sum_{i} \sum_{n} \frac{\mathrm{CE}_{n i j}}{F_{n i j}} \times \frac{F_{n i j}}{F_{i j}} \times \frac{F_{i j}}{E_{i j}} \times \frac{E_{i j}}{Q_{i j}}=\sum_{i} \sum_{n} \mathrm{CF}_{n i j} \times \mathrm{ES}_{n i j} \times T_{i j} \times \mathrm{EI}_{i j}
\end{aligned}
$$

where CI means carbon intensity, represented by CEs GDP per capita; E means total energy consumption, equal to the sum of fossil and non-fossil energy consumption; $\mathrm{CF}$ means carbon coefficient, equal to the ratio of CEs to energy encing factors from 2017 to 2040. In different scenarios, the prediction methods for GDP and population are consistent. The relevant forecast data of GDP and population growth rate come from OECD and UN, respectively, (OECD 2019; 
UN 2018). The GDP and population in year $t$ is calculated in Eqs. (3) and (4), respectively.

$Q_{i}^{t}=Q_{i}^{t-1} \times\left(1+r_{i}^{Q}\right)$

$P_{i}^{t}=P_{i}^{t-1} \times\left(1+r_{i}^{P}\right)$

where $r_{i}^{Q}$ and $r_{i}^{P}$ represents the annual growth rate of value added and employed population in industry $i$ during the period respectively. The future employment population of various industries cannot be directly obtained from observational data. This paper assumes that the trend of the proportion of the employed population in each industry to the total population is stable. Thus, this study calculated the average annual growth rate of the employed population in each industry during 1997-2017. And based on this growth rate, this paper calculated the employment population data of each industry in 2040. Therefore, the predicted GDP and employment is shown in Table 1.

Based on the forecasts given by World Energy Outlook 2018 (IEA 2018), three scenarios ware considered in this

Table 1 Predicted GDP and employment in 2025, 2030, and 2040

\begin{tabular}{llcc}
\hline Variables & 2025 & 2030 & 2040 \\
\hline $\begin{array}{l}\text { Population (Million } \\
\text { people) }\end{array}$ & $1,448.98$ & $1,453.30$ & $1,435.50$ \\
$\begin{array}{l}\text { GDP (Billion Yuan) } \\
\text { Primary }\end{array}$ & $6,235.14$ & $6,735.70$ & $6,601.32$ \\
Secondary & $44,049.37$ & $51,608.10$ & $59,490.79$ \\
Tertiary & $50,662.83$ & $65,194.27$ & $90,661.89$ \\
\hline
\end{tabular}

paper. The three scenarios reflect different energy policies and emission reduction targets. Given that different energy policies will have a significant impact on energy demand and structure (Shahzad et al. 2021), this research mainly focuses on changes in the demand for various types of energy in different scenarios. Current policies scenario (CPS) is a baseline scenario that takes into account the potential environmental impact of documents or policies that have been already published. New policies scenario (NPS) is the medium scenario, which aims to provide policy recommendations for achieving short-term energy and emission targets. In addition to considering the policies that have been implemented by the government, the NPS also considered the official goals and goals already mentioned in the plan. The Nationally Determined Contributions of the Paris Agreement provide an important reference for the government's policy making, although some of them have been supplemented or replaced by more specific documents. NPS reflects the impact of climate and environmental policies on CEs based on these agreements and documents. In this scenario, this paper assumes that the government lacks additional incentives to implement low-carbon strategies. Therefore, when the emission reduction target is a range, this paper assumes that the government is more inclined to achieve its lower threshold. Stainable development scenario (SDS) is a scenario that aims to achieve the climate change target. This scenario aims to achieve the sustainable development targets proposed by the United Nations (SDGs). The assumptions of each scenarios are shown in Table 2.

In CPS, since only policies which formed the specific action plan were considered, China's energy demand in various sectors will change steadily in accordance with current policies, and China's total primary energy demand will continue to

Table 2 Assumptions of each scenarios

\begin{tabular}{|c|c|}
\hline Scenario & Assumptions \\
\hline \multirow[t]{8}{*}{ NPS } & $\begin{array}{l}\text { NDC GHG targets: achieve peak CO2 emissions around 2030, with best efforts to peak early; lower CO2 emissions per unit of GDP } \\
60-65 \% \text { below } 2005 \text { levels by } 2030\end{array}$ \\
\hline & NDC energy target: increase the share of non-fossil fuels in primary energy consumption to $20 \%$ by 2030 \\
\hline & 13th 5-Year Plan targets for 2020 \\
\hline & "Made in China 2025" transition from heavy industry to higher value-added manufacturing \\
\hline & Expand the role of natural gas \\
\hline & ETS expansion to domestic aviation and selected industry sectors \\
\hline & Three-year action plan for cleaner air, announced in July 2018 \\
\hline & $\begin{array}{l}\text { Energy price reform, including more frequent adjustments in oil product prices and reduction in natural gas price for non-residential } \\
\text { consumers }\end{array}$ \\
\hline \multirow[t]{2}{*}{ CPS } & Action Plan for Prevention and Control of Air Pollution \\
\hline & ETS for the power sector \\
\hline \multirow[t]{3}{*}{ SDS } & Universal access to affordable, reliable and modern energy services by 2030 \\
\hline & A substantial reduction in air pollution \\
\hline & $\begin{array}{l}\text { Effective action to combat climate change: to hold the increase in the global average temperature to well below } 2{ }^{\circ} \mathrm{C} \text { above pre- } \\
\text { industrial levels }\end{array}$ \\
\hline
\end{tabular}


rise during 2017-2040. In the NPS, in addition to the current policies, some binding targets that have not yet been transitioned including the energy consumption and carbon emission reduction targets mentioned by the Chinese government in the INDC and the 13th 5-Year Plan have been specifically quantified. This puts more restrictive requirements on the growth of China's energy consumption and CEs, which will curb the growth of energy consumption and CEs, and meanwhile promote the energy transition process including the development of coal-to-combustion and non-fossil energy. And in SDS, in addition to China's current policies and carbon emission reduction targets, SDGs proposed by UN are considered. SDGs put forward additional requirements for non-fossil energy and climate change, which will lead to a substantial increase in the proportion of non-fossil energy consumption and a substantial decline in the growth rate of energy demand. The specific predicted energy data in 2025, 2030, and 2040 are shown in Table 3 . And the predicted energy data in year $t$ is calculated in Eq. (5).

$$
\begin{gathered}
E_{\mathrm{coal}, i}^{t}=E_{\mathrm{coal}, i}^{t-1} \times\left(1+r_{i}^{E_{\mathrm{coal}}}\right) \\
E_{\mathrm{oil}, i}^{t}=E_{\text {oil }, i}^{t-1} \times\left(1+r_{i}^{E_{\text {oil }}}\right) \\
E_{\mathrm{gas}, i}^{t}=E_{\mathrm{gas}, i}^{t-1} \times\left(1+r_{i}^{E_{\mathrm{gas}}}\right) \\
E_{\mathrm{non}, i}^{t}=E_{\mathrm{non}, i}^{t-1} \times\left(1+r_{i}^{E_{\mathrm{non}}}\right)
\end{gathered}
$$

where $E_{\text {coal }, i}^{t}$ represents the coal consumption in industry $i$ in year $t ; E_{\text {oil }, i}^{t}$ represents the oil consumption in industry $i$ in year $t ; E_{\text {gas }, i}^{t}$ represents the gas consumption in industry $i$ in year $t$; $E_{\text {non, } i}^{t}$ represents the non-fossil energy consumption in industry $i$ in year $t ; r_{i}^{E_{\text {coal }}}, r_{i}^{E_{\text {oil }}}, r_{i}^{E_{\text {gas }}}$ and $r_{i}^{E_{\text {non }}}$ represents the annual growth rate of coal, oil, gas, and non-fossil energy in industry $i$ during the period, respectively.

\section{Decomposition analysis}

\section{LMDI method}

As mentioned above, IDA model was widely utilized in the research related CEs reduction. In this paper, we applied additive LMDI model to evaluate the specific influence of various drivers on the evolution trend of China's CEs. In particular, this study considered the impact of non-fossil energy consumption on CEs. The evaluation trend of CEs can be expressed as Eq. (6).

$\Delta C E=C E^{t}-C E^{0}=\Delta C F+\Delta E S+\Delta T+\Delta E I+\Delta A+\Delta P$

where $\triangle C E$ stands for the evaluation of China's CEs during this period; $C E^{t}$ and $C E^{0}$ stands for China's CEs in year $t$ and year 0 , respectively; $\Delta \mathrm{CF}, \Delta \mathrm{ES}, \Delta T, \Delta \mathrm{EI}, \Delta A$ and $\Delta P$ stands for the changes of China's CEs derived from various drivers. The impact of each driver can be calculated as Eqs. (7-12).

$$
\begin{aligned}
& \Delta \mathrm{CF}=\sum_{i} \sum_{n}\left[\left(\mathrm{CE}_{n i}^{t}-\mathrm{CE}_{n i}^{0}\right) /\left(\ln \mathrm{CE}_{n i}^{t}-\ln \mathrm{CE}_{n i}^{0}\right)\right] \times\left(\ln \mathrm{CF}_{n i}^{t}-\ln \mathrm{CF}_{n i}^{0}\right) \\
& \Delta \mathrm{ES}=\sum_{i} \sum_{n}\left[\left(\mathrm{CE}_{n i}^{t}-\mathrm{CE}_{n i}^{0}\right) /\left(\ln \mathrm{CE}_{n i}^{t}-\ln \mathrm{CE}_{n i}^{0}\right)\right] \times\left(\ln \mathrm{ES}_{n i}^{t}-\ln \mathrm{ES}_{n i}^{0}\right) \\
& \Delta T=\sum_{i} \sum_{n}\left[\left(\mathrm{CE}_{n i}^{t}-\mathrm{CE}_{n i}^{0}\right) /\left(\ln \mathrm{CE}_{n i}^{t}-\ln \mathrm{CE}_{n i}^{0}\right)\right] \times\left(\ln T_{n i}^{t}-\ln T_{n i}^{0}\right)
\end{aligned}
$$

\begin{tabular}{|c|c|c|c|c|c|c|c|c|c|c|}
\hline \multirow[t]{2}{*}{ Sector } & \multirow[t]{2}{*}{ Energy (Mtces) } & \multicolumn{3}{|l|}{2025} & \multicolumn{3}{|l|}{2030} & \multicolumn{3}{|l|}{2040} \\
\hline & & CPS & NPS & SDS & CPS & NPS & SDS & CPS & NPS & SDS \\
\hline \multirow[t]{4}{*}{ Primary } & Coal & 112.86 & 111.43 & 105.71 & 117.14 & 110.56 & 102.86 & 121.43 & 109.21 & 97.14 \\
\hline & Oil & 54.91 & 54.91 & 53.58 & 62.90 & 61.57 & 58.57 & 75.55 & 70.89 & 64.90 \\
\hline & Gas & 18.57 & 18.57 & 20.00 & 21.43 & 21.43 & 20.00 & 22.86 & 24.29 & 22.86 \\
\hline & Non-fossil & 2.86 & 2.86 & 5.71 & 4.29 & 5.71 & 10.00 & 5.71 & 5.71 & 11.43 \\
\hline \multirow[t]{4}{*}{ Secondary } & Coal & $2,652.86$ & $2,555.71$ & $2,172.86$ & $2,752.86$ & $2,500.00$ & $1,750.00$ & $2,875.71$ & $2,270.00$ & 948.57 \\
\hline & Oil & 161.43 & 155.71 & 144.29 & 152.86 & 140.00 & 118.57 & 131.43 & 112.86 & 71.43 \\
\hline & Gas & 340.00 & 322.86 & 324.29 & 437.14 & 394.29 & 412.86 & 604.29 & 520.00 & 521.43 \\
\hline & Non-fossil & 592.86 & 617.14 & 712.86 & 720.00 & 791.43 & $1,011.43$ & 957.14 & $1,130.00$ & $1,605.71$ \\
\hline \multirow[t]{4}{*}{ Tertiary } & Coal & 98.57 & 68.57 & 67.14 & 84.29 & 47.14 & 41.43 & 64.29 & 12.86 & 4.29 \\
\hline & Oil & 644.29 & 594.29 & 534.29 & 712.86 & 622.86 & 472.86 & 765.71 & 612.86 & 290.00 \\
\hline & Gas & 171.43 & 174.29 & 170.00 & 198.57 & 201.43 & 204.29 & 241.43 & 231.43 & 220.00 \\
\hline & Non-fossil & 151.43 & 157.14 & 140.00 & 151.43 & 161.43 & 128.57 & 160.00 & 175.71 & 167.14 \\
\hline
\end{tabular}

$\Delta \mathrm{EI}=\sum_{i} \sum_{n}\left[\left(\mathrm{CE}_{n i}^{t}-\mathrm{CE}_{n i}^{0}\right) /\left(\ln \mathrm{CE}_{n i}^{t}-\ln \mathrm{CE}_{n i}^{0}\right)\right] \times\left(\ln \mathrm{EI}_{n i}^{t}-\ln \mathrm{EI}_{n i}^{0}\right)$

$$
\Delta A=\sum_{i} \sum_{n}\left[\left(\mathrm{CE}_{n i}^{t}-\mathrm{CE}_{n i}^{0}\right) /\left(\ln \mathrm{CE}_{n i}^{t}-\ln \mathrm{CE}_{n i}^{0}\right)\right] \times\left(\ln A_{n i}^{t}-\ln A_{n i}^{0}\right)
$$

Table 3 Predicted energy data in 2025, 2030, and 2040 
$\Delta P=\sum_{i} \sum_{n}\left[\left(\mathrm{CE}_{n i}^{t}-\mathrm{CE}_{n i}^{0}\right) /\left(\ln \mathrm{CE}_{n i}^{t}-\ln \mathrm{CE}_{n i}^{0}\right)\right] \times\left(\ln P_{n i}^{t}-\ln P_{n i}^{0}\right)$

In many studies, due to the specific characteristics of energy resources, researchers often assume that the carbon coefficient is constant. Therefore, in this paper, the carbon coefficient effect was ignored, and the impact of the remaining five driving factors on China's CEs changes were evaluated.

\section{ST-LMDI method}

At the provincial level, to make the CI of different provinces comparable, this paper applied the ST-LMDI model to assess the requirements and potential of CEs reduction in different provinces. Different from the traditional LMDI method, ST-LMDI model can analyze the differences between CI of each province and the target value across temporal and spatial dimensions by constructing a benchmark. Spatial-temporal comparative analysis includes three methods: bilateral-regional (B-R), radial-regional (R-R) and multi-regional (M-R) analysis. The B-R model is mainly used for comparative analysis between two regions. The R-R model is only suitable for static comparative analysis in a specific year. In dynamic research, the benchmark in the R-R model will change over time, and the final calculated results between various years are not comparable. The M-R model overcomes the shortcomings of the B-R and R-R models. In the $\mathrm{M}-\mathrm{R}$ model, the comparison benchmark for each region is constant. And the calculation results between different years are comparable. This paper applied M-R comparative analysis to study the differences between each provinces and the benchmark. In this paper, the projected CI in 2040 of the three scenarios was established as the benchmark. Then, the CI of each province in 2017 was compared with the benchmark, respectively. The specific calculation method is shown as Eq. (13).

$\Delta \mathrm{CI}_{j}=\mathrm{CI}_{j}^{t} / \mathrm{CI}_{\mu}=\Delta \mathrm{CF}_{j} \times \Delta \mathrm{ES}_{j} \times \Delta T_{j} \times \Delta \mathrm{EI}_{j}$

where $\Delta \mathrm{CI}$ stands for the spatial differences of $\mathrm{CI} ; \mathrm{CI}_{j}$ and $\mathrm{CI}_{\mu}$ stands for $\mathrm{CI}$ in province $j$ and the benchmark, respectively; $\Delta \mathrm{CF}, \Delta \mathrm{ES}, \Delta T$, and $\Delta \mathrm{EI}$ stands for the spatial differences of CI caused by various factors. Since the decomposition object was an intensity indicator, this paper utilized the multiplicative decomposition method to evaluate the spatial differences of each factor. The specific calculation method is shown in Eqs. (14, 15, 16, and 17).
$\Delta \mathrm{CF}_{j}=\exp \left[\sum_{i} \sum_{n} \frac{L\left(C_{n i j}^{t} / G_{i j}^{t}, C_{n i \mu} / G_{i \mu}\right)}{L\left(\mathrm{CI}_{i j}^{t}, \mathrm{CI}_{i \mu}\right)} \cdot \ln \left(\frac{\mathrm{CF}_{n i j}^{t}}{\mathrm{CF}_{n i u}}\right)\right]$

$\Delta \mathrm{ES}_{j}=\exp \left[\sum_{i} \sum_{n} \frac{L\left(C_{n i j}^{t} / G_{i j}^{t}, C_{n i \mu} / G_{i \mu}\right)}{L\left(\mathrm{CI}_{i j}^{t}, \mathrm{CI}_{i \mu}\right)} \cdot \ln \left(\frac{\mathrm{ES}_{n i j}^{t}}{\mathrm{ES}_{n i u}}\right)\right]$

$\Delta T_{j}=\exp \left[\sum_{i} \sum_{n} \frac{L\left(C_{n i j}^{t} / G_{i j}^{t}, C_{n i \mu} / G_{i \mu}\right)}{L\left(\mathrm{CI}_{i j}^{t}, \mathrm{CI}_{i \mu}\right)} \cdot \ln \left(\frac{T_{n i j}^{t}}{T_{n i u}}\right)\right]$

$\Delta \mathrm{EI}_{j}=\exp \left[\sum_{i} \sum_{n} \frac{L\left(C_{n i j}^{t} / G_{i j}^{t}, C_{n i \mu} / G_{i \mu}\right)}{L\left(\mathrm{CI}_{i j}^{t}, \mathrm{CI}_{i \mu}\right)} \cdot \ln \left(\frac{\mathrm{EI}_{n i j}^{t}}{\mathrm{EI}_{n i u}}\right)\right]$

For the same reason, in this section, this paper assumed that the carbon coefficient is constant during studying period. The spatial differences of the carbon coefficient effect on CI have not been evaluated, and the impact of remaining three factors was analyzed.

\section{Data description}

Due to the limitations of data acquisition, this paper only studied the data of 30 provinces in China (except Hong Kong, Macau, Taiwan, and Tibet) from 1997 to 2040. The historical GDP and Population data was obtained from "National Bureau of Statistics of China" (NBSC 19982018a). The projected GDP data were from OECD (OECD 2019) and the projected population data were from the United Nation (UN 2018). The GDP data of each year were calculated based on the constant prices of sub-sector of each province and in 2010. The historical fossil energy data were obtained from "China Energy Statistics Yearbook" (NBSC 1998-2018b). The historical non-fossil energy data were acquired from "China Electricity Statistical Yearbook" (NBSC 1998-2018c). Besides, the projected fossil and non-fossil energy data were both acquired from "World Energy Outlook 2018" published by IEA (IEA 2018). According to Yuan et al. (2018), the economic indicator of power generation (tce/kwh) was utilized to convert the power generation by non-fossil energy (kwh) to energy consumption (tce). According to the method published by the IPCC in 2006 (IPCC 2006), historical CEs were calculated based on fossil energy consumption data. This paper 
considered four types of energy including fuel coal, fuel oil, fuel gas, and non-fossil energy.

\section{Results}

\section{Evaluation trend and drivers of China's CEs}

China's CEs increased dramatically from 2931.6 to 9865.83Mtons during 1997-2017, with an average annual growth rate of $6.26 \%$ (Fig. 1). This process can be divided into four stages according to CEs growth characteristics. The first stage is 1997-2002. The annual growth rate of CEs in this stage was $3.69 \%$. The second stage is $2002-2007$. During this period, the CEs increased significantly, with an average annual growth rate of $14.19 \%$. The third stage is 2007-2012. The CEs growth at this stage is relatively flat, with an average annual growth rate of $6.85 \%$. The fourth stage is 2012-2017. The CEs hardly increased, with an average annual growth rate of $0.77 \%$. From industrial perspective, the CEs of different industries varied greatly. The primary industry's CEs increased from 76.7Mtons in 1997 to 139.44 Mtons in 2017 , with an average annual growth rate of $3.03 \%$. The secondary industry's CEs increased from 2447.1Mtons in 1997 to 8261.85 Mtons in 2017, with an average annual growth rate of $6.27 \%$. The tertiary industry's CEs increased from 407.8Mtons in 1997 to 1464.54Mtons in 2017 , with an average annual growth rate of $6.60 \%$. From proportion perspective, the secondary industry contributed the most to CEs, accounting for $83.74 \%$ of national total in 2017. The CEs of tertiary industry has the fastest growth rate. In 1997, the tertiary industry accounted for $13.91 \%$ of the national total CEs. However in 2017, this proportion rose to $14.84 \%$.

LMDI model was applied to analyze the drivers of China's CEs growth in these four period. Results are shown in Fig. 2. From 1997 to 2002, the effects of fossil energy structure and energy consumption structure hardly inhibited growth of CEs in various industries. It is mainly attributed to the slow development of energy structure optimization and non-fossil energy application ( $\mathrm{Li}$ et al. 2017a). Energy intensity effect was the leading driver for all three industries to restrain the growth of CEs. Benefiting from technological progress, the energy efficiency of the secondary and tertiary industries has been significantly improved. Energy intensity has reduced the CEs in secondary and tertiary industries by $42.19 \%$ ( -1022.85 Mtons) and $33.49 \%$ (-136.13Mtons) in this period, respectively. While it only reduced the CEs of the primary industry by $11.21 \%$ ( $-8.56 \mathrm{Mtons})$. Activity effect was the leading force to promote the growth of CEs. From 1997 to 2002, the average annual growth rate of value added in secondary and tertiary industries was $9.12 \%$ and $9.62 \%$, while that of the primary industry was only $2.88 \%$. Therefore, the promoting role of activity effect on CEs in secondary (1693.65Mtons, 69.87\%) and tertiary industries (162.34Mtons, $39.94 \%$ ) was much greater than that of the primary industry (11.85Mtons, $15.53 \%)$. The population effect is positively correlated with changes in the employment number in various industries. During this period, the employment number in primary and tertiary industries increased by $5.17 \%$ and $13.70 \%$. Therefore, the population effect increased the CEs of primary and tertiary industries by $5.5 \%$ (4.20Mtons) and $13.87 \%$ (56.37Mtons), respectively. However, due to the development of industrialization process, the employment number in secondary industry dropped by $5.23 \%$ during this period. This also led to a population effect that reduced the secondary industry's CEs by $6.57 \%$ (-159.31Mtons).

From 2002 to 2007, due to the rapid expansion of the industries, the employees and the added value of secondary and tertiary industries increased rapidly, which became the main reason for promoting the growth of CEs. Population and activity effect promoted the secondary industry's CEs growth by $35.58 \%$ (1037.29Mtons) and $20.60 \%$ (100.02Mtons), and promoted the tertiary industry's CEs growth by $70.35 \%$ (2050.70Mtons) and $58.77 \%$ (285.38Mtons). But for the primary industry, due to the continuous reduction of employees, the population effect
Fig. 1 China's CEs during 1997-2017

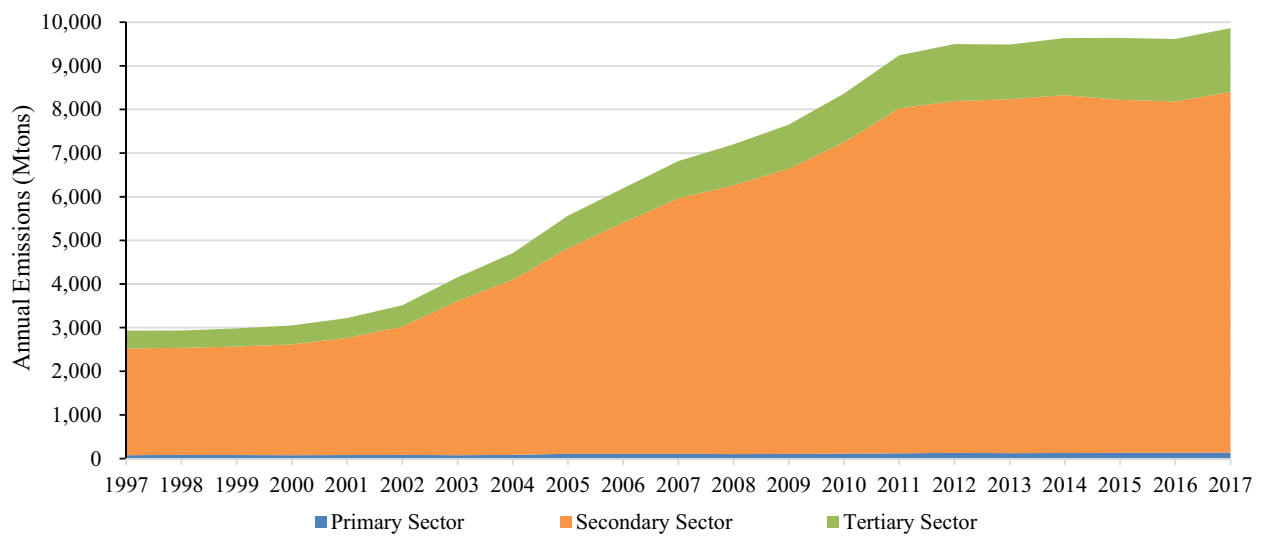




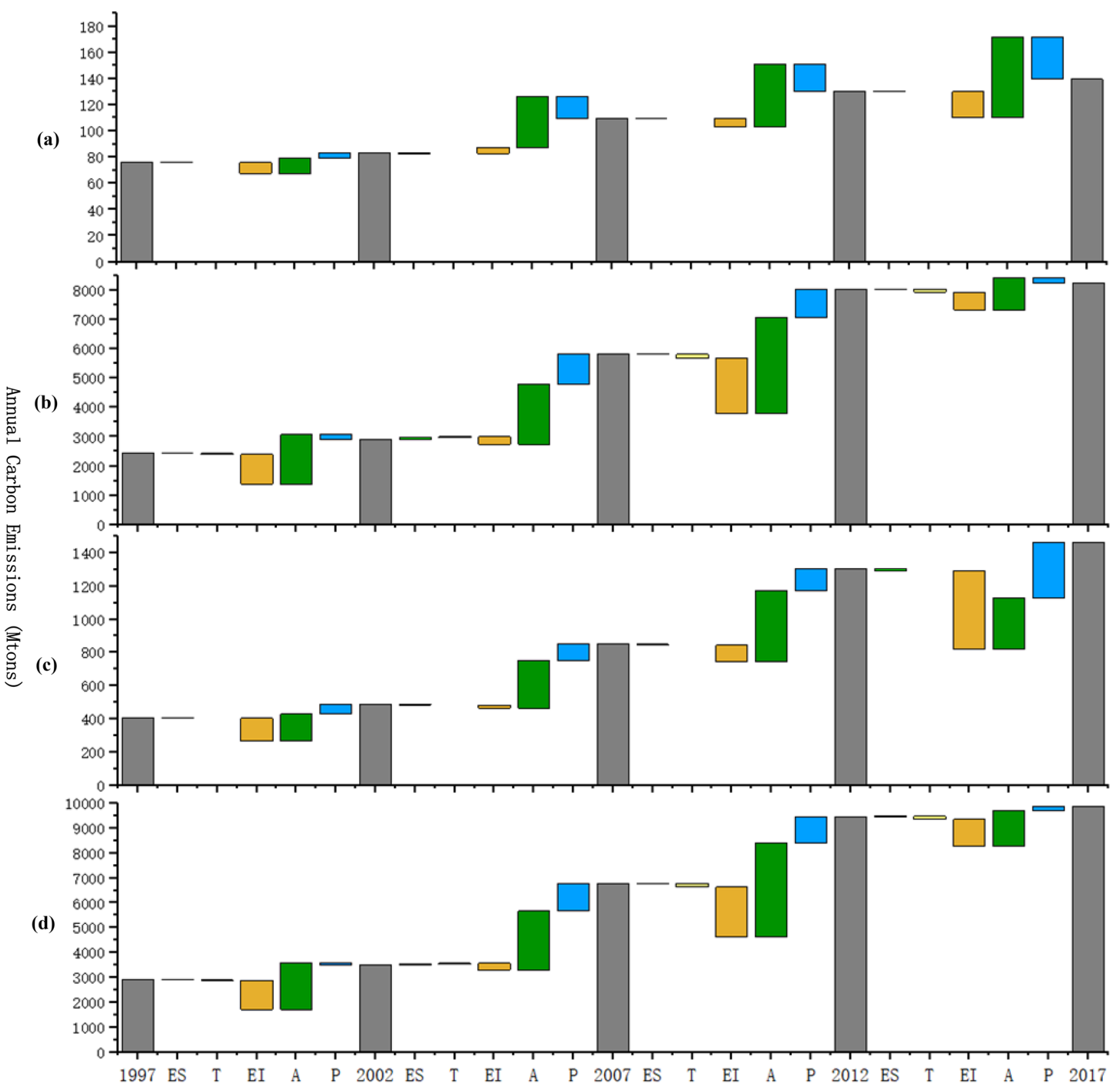

Fig. 2 Decomposition result of historical CEs during 1997-2017 a Primary sector; b Secondary sector; c Tertiary sector; d National total

reduced its CEs by $19.48 \%$ (-16.26Mtons). At this stage, various industries paid their attention to scale expansion, ignoring energy structure improvement and technological progress. Therefore, the effect of fossil energy structure, energy consumption structure, and energy intensity on CEs changes were not significant.

From 2007 to 2012, the scale of each industry continued to expansion, and the value added of each industry grew rapidly. Activity effect became the main driver for promoting the CEs growth, which promoted primary industry's CEs by $43.92 \%$ (48.22Mtons), secondary industry's CEs by $56.47 \%$ (3290.39Mtons), and tertiary industry's CEs by $50.28 \%$ (427.29Mtons). Due to the increasing employment number, population effect also promoted the growth of CEs in secondary $(16.35 \%, 952.66 \mathrm{Mtons})$ and tertiary $(15.65 \%$, 133.03Mtons) industries. Benefiting from the continuous improvement of mechanization, the employment number in primary industry gradually decreased, and the population effect inhibited CEs growth in primary industry by $19.01 \%$ ( -20.87 Mtons). Besides, during this period, due to the transformation from extensive to energy-saving especially in secondary industry, energy intensity dramatically 
curbed the growth of CEs from the primary industry by $6.2 \%$ ( $-6.8 \mathrm{Mtons}$ ), from the secondary industry by $32.61 \%$ ( $-1900.22 \mathrm{Mtons})$, and from third industry's by $11.28 \%$ (-95.87Mtons). Particularly, benefiting from the application of non-fossil energy in secondary industry, the energy consumption structure effect has slightly restrained the growth of CEs in secondary industry (2.23\%, $-129.70 \mathrm{Mtons})$.

From 2012 to 2017, due to the implementation of environmental protection policies and the improvement of energy efficiency, energy intensity was the dominant driver restraining the CEs growth, which restrained CEs growth from the primary industry by $15.14 \%$ ( $-19.73 \mathrm{Mtons})$, secondary industry by $6.77 \%$ ( -543.31 Mtons), and tertiary industry by $36.39 \%$ ( -475.69 Mtons). Activity effect was the main driver promoting growth of CEs especially in primary industry $(46.99 \%, 61.23 \mathrm{Mtons})$. Benefiting from poverty alleviation and agricultural policies, output value of primary industry has grown rapidly at this stage. Besides, activity effect promoted CEs growth from secondary industry by
$12.76 \%$ (1024.85Mtons), and tertiary industry by $23.69 \%$ (309.65Mtons) respectively. It is worth noting that there has been a clear labor transfer between industries at this stage. A large amount of labor resources have been transferred from primary to tertiary industry. This caused the population effect to promote the tertiary industry's CEs by $25.68 \%$ (335.70Mtons), while inhibited the primary industry's CEs growth by $24.66 \%$ ( $-32.13 \mathrm{Mtons})$. For the secondary industry, energy consumption structure $(1.9 \%,-152.54 \mathrm{Mtons})$ and population $(1.40 \%,-112.25 \mathrm{Mtons})$ effect respectively had a slight inhibitory effect.

\section{Scenario analysis of China's CEs}

According to the assumptions in Sect. 3.2, this paper predicted the CEs in China during 2017-2040. Figures 3 and 4 presented the evolution trend of CEs and CI of various industries in different scenarios from 2017 to 2040, respectively. In CPS, China's CEs show an overall upward trend

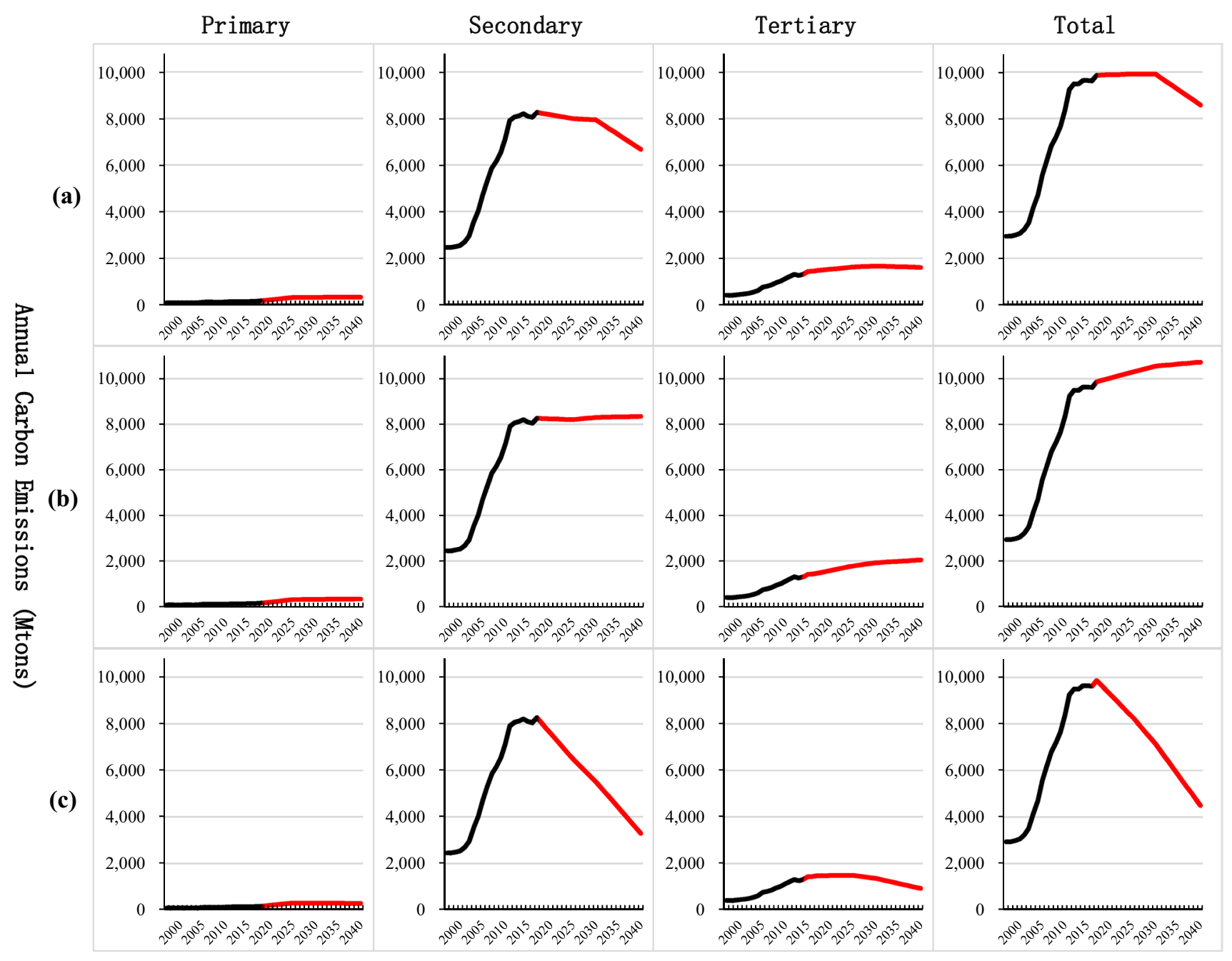

Fig. 3 China's CEs during 1997-2040 in different sector. a New policies scenario; b Current policies 


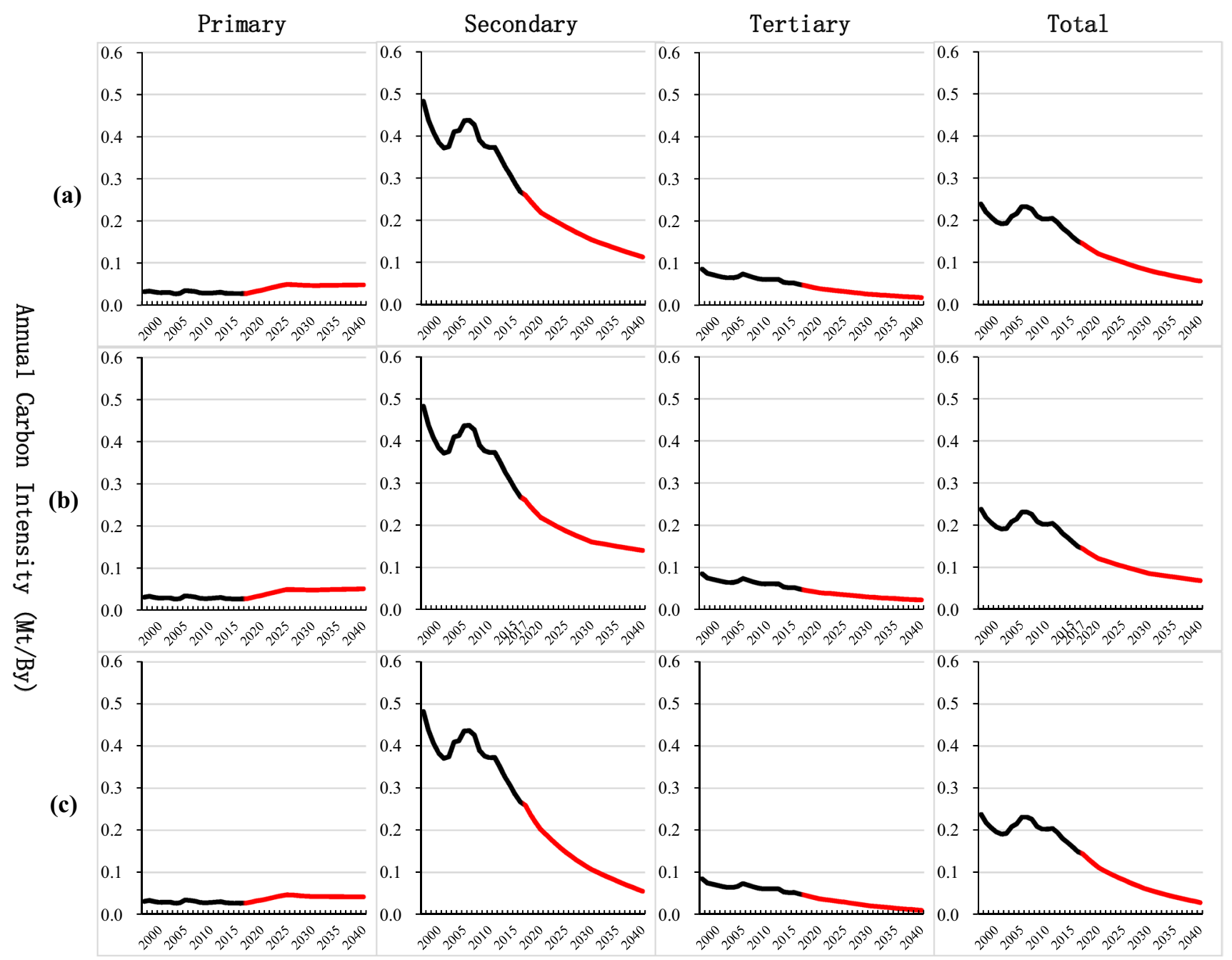

Fig. 4 China's CI during 1997-2040 in different sector. a New policies scenario; b Current policies scenario; c Sustainable development scenario

and will reach 10,729.00Mtons in 2040. The CI will continue to decrease from $0.144 \mathrm{Mt} / \mathrm{By}$ in 2017 to $0.085 \mathrm{Mt} /$ By in 2030 and $0.068 \mathrm{Mt} / \mathrm{By}$ in 2040. Thus, the total CEs of China will not reach the peak before 2040, and the 2030 CI reduction target will not be achieved. From an industrial perspective, the increase in CEs is dominantly attributed to tertiary industry. The CEs increase from 1464.54Mtons in 2017 to 2048.59 Mtons in 2040 . This is mainly due to the process of industrial upgrading. Benefiting from the dramatically expansion of the industries, the proportion of the tertiary industry will rise from $46.04 \%$ in 2017 to $57.84 \%$ in 2040.

In NPS, China's CEs will continue to grow and reach the peak of 9917.79Mtons in 2030. Then, the CEs will begin to decline and reach $8584.45 \mathrm{Mtons}$ in 2040 . It is worth noting that CEs from the tertiary industry continue to increase from 1464.54Mtons in 2017 to 1601.1 Mtons in 2040. The key to helping China's CEs peak in 2030 is in the secondary industry. From 2017 to 2030, the CEs of secondary industry drop from 8261.85 to $7946.47 \mathrm{Mtons}$. The CI continues to decrease to $0.080 \mathrm{Mt} / \mathrm{By}$ in 2030 , with a decrease rate of $60.19 \%$ compared to that of 2005 . This also means that China achieves the lower limit of 2030 CEs reduction target.

In SDS, the CEs will continuously decrease from 2017 to 2040 . This is mainly caused by the significant drop of CEs from the secondary industry. Subject to strict energy consumption and emission policies, from 2017 to 2040, the proportion of fossil energy consumption in secondary industry dropped from 87.14 to $48.98 \%$, and the energy intensity decreased from 0.11 to $0.05 \mathrm{Mt} / \mathrm{By}$. It caused that CEs in secondary industry dropped from 8261.85 to 3294.29Mtons. Particularly, the CEs of the primary and tertiary industries have shown an increasing trend between 2017 and 2025. This means that the energy and emission policies of the government are lagging in primary and tertiary industries, and the relevant policies mainly have effects on the secondary 
industry. Besides, the $\mathrm{CI}$ decreased to $0.058 \mathrm{Mt} / \mathrm{By}$ in 2030 , with a decrease rate of $72.46 \%$ compared to that of 2005 . This means that China better achieves its 2030 CEs reduction target, and sustainable energy and industrial policies can play a huge role on environmental improvement and energy conservation.

\section{Decomposition analysis of predicted}

According to the LMDI method, this paper analyzed China's CEs in different scenarios during 2017-2040 at industrial level. The decomposition results are shown in Fig. 5. In CPS, with the rapid expansion of the scale of the industry, the activity effect promotes the continuous growth of China's CEs, which respectively contributes to CEs increasing by $191.80 \%$ (267.79Mtons) in primary industry, $26.38 \%$ (2179.27Mtons) in secondary industry, and 55.89\% (818.49Mtons) in tertiary industry. In view of the targeted energy policies for energy-intensive industries, energy intensity as a leading force reduces CEs in secondary industry by $17.19 \%$ ( -1420.18 Mtons), and in tertiary industry by $50.98 \%$ ( -1993.59 Mtons). However for primary industry, due to the increase of energy consumption, energy intensity promotes the CEs growth by $124.04 \%$ (173.18Mtons). With the application of non-fossil energy, energy consumption structure effect inhibits the CEs growth in primary industry by $3.03 \%$ ( $-4.23 \mathrm{Mtons})$, the secondary industry by $4.95 \%$ ( $-408.71 \mathrm{Mtons}$ ), and the tertiary industry by $14.95 \%$ ( -218.87 Mtons). The result of population effect is a manifestation of labor transfer between industries. From 2017 to 2040, the employment number in primary and secondary industries decreases by $75.71 \%$ and $11.38 \%$, while the employment number in tertiary industry increased by $60.72 \%$. This is in line with the trend of agricultural mechanization and industrial intelligence. It is worth noting that the fossil energy structure has a 2.9\% (239.79Mtons) promotion effect on CEs growth in secondary industry. It means that current fossil energy policy cannot curb growth of CEs process.

In NPS, activity effect is still the main impact factor, which increases CEs in primary industry by $183.37 \%$ (256.02Mtons), secondary industry by $36.96 \%$ (3052.83Mtons), and tertiary industry by $53.5 \%$ (783.46Mtons). In NPS, the government implements a series of stricter energy consumption and energy substitution policies. Energy intensity effects have a more obvious effect

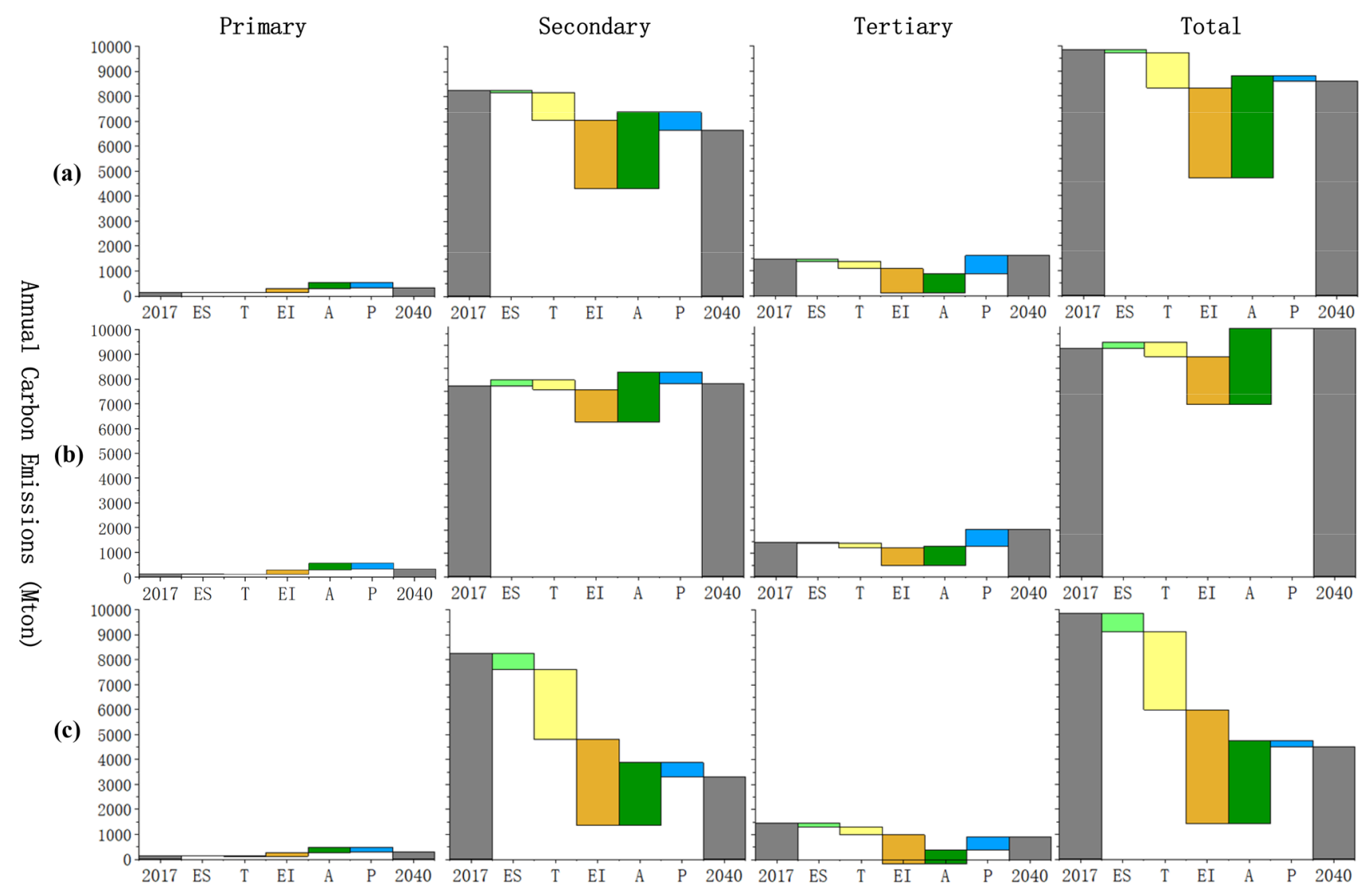

Fig. 5 Decomposition result of China's CEs during 1997-2040 in different sector. a New policies scenario; b Current policies scenario; c Sustainable development scenario 
on CEs decrease in secondary $(32.96 \%,-2722.41$ Mtons $)$ and tertiary $(66.87 \%,-979.33 \mathrm{Mtons})$ industries. The new policies require the non-fossil energy consumption to reach $24.85 \%$ in 2040 , which reduce CEs by $3.08 \%$ (-4.3Mtons) in primary industry, $13.60 \%$ ( $-1123.07 \mathrm{Mtons})$ in secondary industry, and $19.17 \%$ (-280.70Mtons) in tertiary industry. Besides, the proportion of coal consumption drop to $45.36 \%$ in 2040 . This makes the fossil energy structure effect slightly reduce the CEs from the secondary industry (1.07\%, - 88.32Mtons). Compared with the development of non-fossil energy, the impact of fossil energy structure optimization on CEs reduction is limited.

In SDS, the activity effect on CEs growth is further suppressed, increasing CEs in primary industry by $169.67 \%$ (236.89Mtons), in secondary industry by $30.51 \%$ (2520.03Mtons), and in tertiary industry by $39.30 \%$ (575.60Mtons). Energy policies in SDS further reduce the energy intensity. In secondary and tertiary industries, energy intensity effect reduces CEs by $41.77 \%$ ( -3450.21 Mtons) and $80.54 \%$ ( $-1179.45 \mathrm{Mtons})$, respectively. Due to the substantial decline in coal consumption and the increase of non-fossil energy consumption, fossil energy structure and energy consumption structure effects have had significant effects in reducing CEs. Especially for the energy consumption structure effect, in SDS, the proportion of the non-fossil energy consumption is $44.33 \%$ in 2040 , which results in a reduction in CEs by $6.26 \%$ ( $-8.74 \mathrm{Mtons}$ ) in primary industry, $33.84 \%$ ( $-2794.70 \mathrm{Mtons})$ in secondary industry, $21.25 \%$ ( $-311.21 \mathrm{Mtons})$ in tertiary industry. This further proves that vigorously developing non-fossil energy is of great significance for achieving CEs reduction targets.

\section{Provincial emission analysis}

\section{Evaluation trend of provincial emissions}

The dynamic of provincial CEs during 1997-2017 is shown in Fig. 6. The CEs have undergone different evolutionary trends at the provincial level during 1997-2017. In primary industry, due to the continuous expansion of the industry, the most provinces have experienced rapid growth in CEs except Beijing, Shanxi, Shanghai, Chongqing, and Guizhou. The decrease in fuel coal consumption led to CEs reduction of Shanxi, Shanghai, Chongqing and Guizhou by $46.23 \%$, 95\%, 70.34\% and 30\%, respectively. For Beijing, the CEs reduction was mainly due the decrease of fuel oil consumption. On the contrary, during this period, Hebei, Inner Mongolia, Heilongjiang and Sichuan had the largest CEs growth in the primary industry, which increased by $4.54 \mathrm{Mtons}$ (189.17\%), 10.56Mtons (440.00\%), 7.51Mtons (144.42\%), and 4.14Mtons (591.43\%), respectively. It is mainly caused by the growth of fuel coal and fuel oil consumption. In secondary industry, only CEs in Beijing declined between
1997 and 2017. This is mainly due to the shutdown or transfer of energy-intensive industries, which is Beijing's great achievement in easing the functions of the capital (Liu et al. 2019). The CEs of secondary industry in other provinces have experienced different degrees of growth especially for Hebei, Inner Mongolia, Jiangsu and Shandong. With the rapid increase in industrial output value, industrial energy, especially coal consumption in various provinces has increased significantly (Qiao et al. 2019). This directly causes a growth of CEs. In tertiary industry, the CEs of all provinces showed a clear upward trend, which is consistent with the continuous expansion of the tertiary industry. Especially in developed provinces such as Beijing, Shanghai, Jiangsu, Zhejiang, Shandong, and Guangdong, rapid development of the tertiary industry has also driven their energy related CEs to grow rapidly by $314.24 \%$ (39.28Mtons), $416.67 \%$ (63.75Mtons), $311.72 \%$ (47.07Mtons), $345.43 \%$ (43.87Mtons), $424.57 \%$ (73.45Mtons), and $401.23 \%$ (101.11Mtons), respectively. In particular, there are clear differences in the CEs growth pattern among secondary and the tertiary industries. The CEs growth of secondary industry mainly derived from coal consumption, while that of the tertiary industry mainly derived from oil consumption (Wang et al. 2019).

Figure 7 showed the changes on CI at the provincial level from 1997 to 2017. Form 1997 to 2002, the CI of most provinces declined except Shanxi, Hainan and Ningxia. This is mainly affected by the secondary industry. Only the secondary industry's CI in Hainan and Ningxia increased between 1997 and 2002. Particularly, the CI of various industries in Shanxi showed a downward trend during this period. However, due to the significant growth in the proportion of the secondary industry, its CI has increased slightly. From 2002 to 2007, the CI of 18 provinces showed an increasing trend. Especially for Fujian, Shandong, and Yunnan, the growth rate of CI was all above $30 \%$. This is the result of extensive economic development. It is worth noting that the CI of Beijing and Shanghai both decreased more than $20 \%$ during this period, especially the CI of the secondary industry, which decreased more than $30 \%$. It depends on the city positioning of Beijing and Shanghai. As an international metropolis, Beijing and Shanghai have been committed to alleviating energy-intensive industries, but these policies has also led to the CEs growth in neighboring provinces (Sun et al. 2019). From 2007 to 2012, local governments introduced a series of environmental and energy policies, and only Ningxia and Xinjiang showed a growth in CI. It is dominantly caused by the increase of CEs of secondary industry. Due to the relatively backward development, the economic growth of Ningxia and Xinjiang is more dependent on resource-driven development of the coal industry, which has caused the continuous increase of CEs. From 2012 to 2017, only CI in Xinjiang showed a growth trend. Moreover, from industrial 


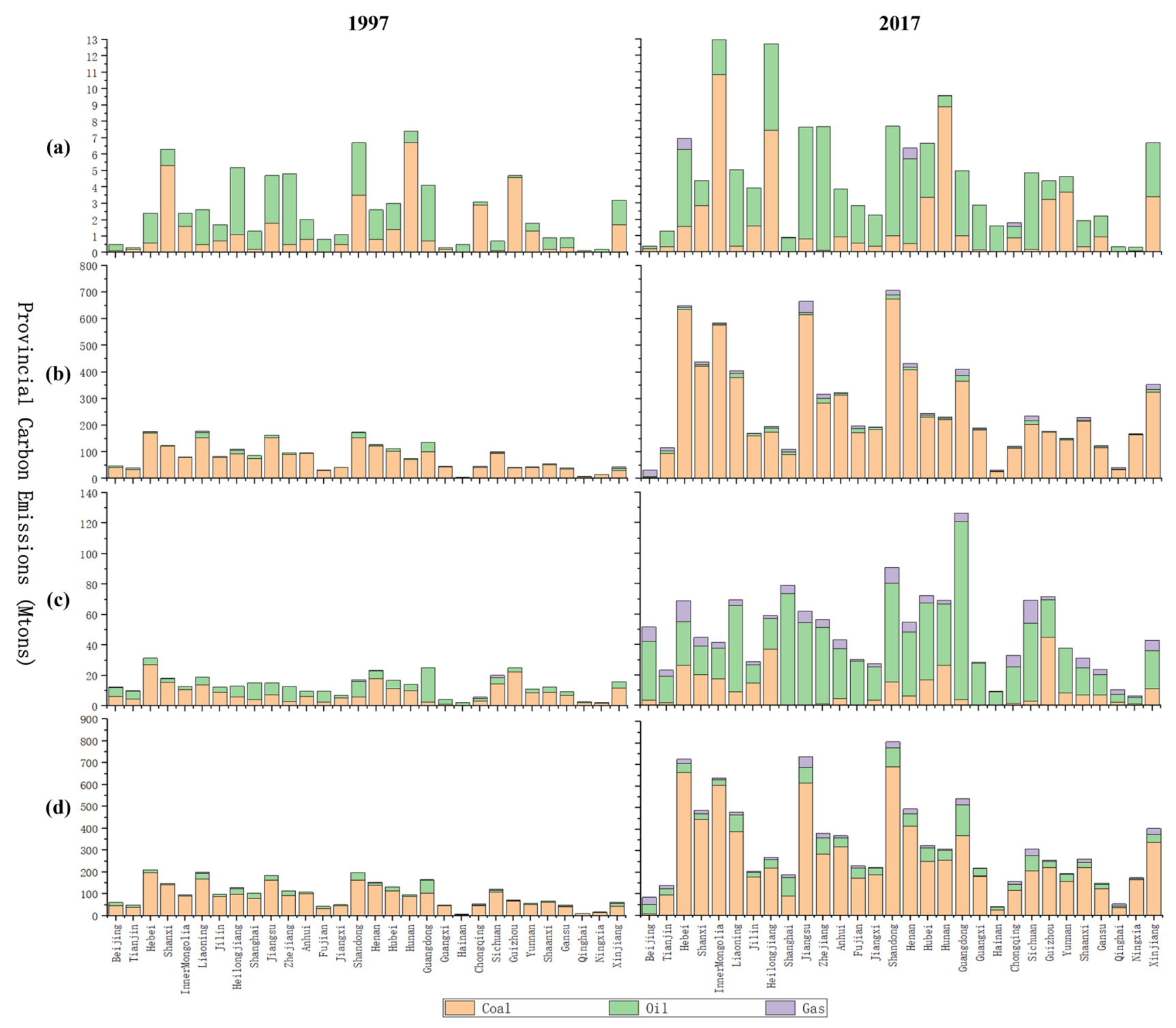

Fig. 6 Provincial CEs during 1997-2017 a Primary sector; b Secondary sector; c Tertiary sector; d National total

perspective, the $\mathrm{CI}$ of the secondary and tertiary industries in most provinces has declined except Xinjiang. Governments should give more policy support to Xinjiang, and develop clean energy in accordance with local conditions to reduce CEs.

\section{Provincial decomposition results}

Analyzing the spatial difference of $\mathrm{CI}$ between each province and the ideal state is of great significance for identifying key provinces and assessing potential approaches for CEs reduction. Based on the above analysis, the SDS is the most ideal scenario. Therefore, in this section, China's average CI in 2040 under SDS is established as a benchmark, and STLMDI model was applied to evaluate the spatial differences between provinces and the benchmark. Table 4 presents the spatial-temporal decomposition results. For primary industry, the spatial differences mainly depends on fossil energy structure and energy intensity effects. With the process of agricultural mechanization, modern large-scale agricultural machinery has gradually replaced manpower, leading to a dramatic growth of energy consumption in 2040 (Lin and Liu 2017). The energy intensity effect of most provinces is lower than the benchmark except Tianjin, Inner Mongolia, Heilongjiang, and Shanghai. Inner Mongolia and Heilongjiang are the provinces with the largest energy consumption in primary industry, accounting for about $20 \%$ of national total. Reducing their energy consumption is critical to controlling CEs in primary industry. The energy structure effect of Shanxi, Inner Mongolia, Hunan, Guizhou, and Yunnan 


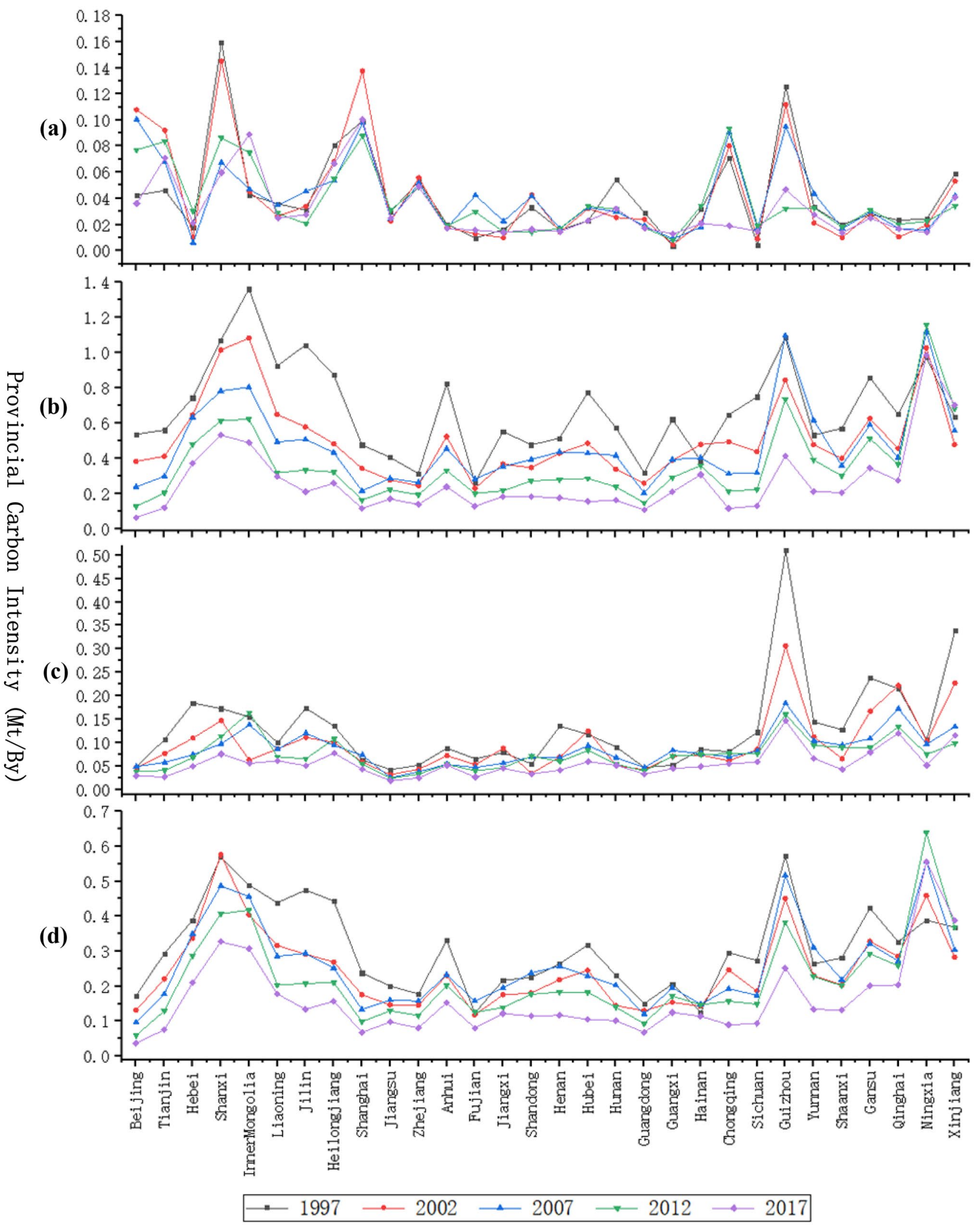

Fig. 7 Provincial CI during 1997-2017 a Primary sector; b Secondary sector; c Tertiary sector; d National total 
Table 4 Decomposition result of provincial CI during 2017-2040 in different sector from sustainable development scenario

\begin{tabular}{|c|c|c|c|c|c|c|c|c|c|c|c|c|}
\hline \multirow[t]{2}{*}{ Provinces } & \multicolumn{3}{|c|}{ Primary } & \multicolumn{3}{|c|}{ Secondary } & \multicolumn{3}{|c|}{ Tertiary } & \multicolumn{3}{|l|}{ Total } \\
\hline & ES & $T$ & EI & ES & $T$ & EI & ES & $T$ & EI & ES & $T$ & EI \\
\hline Beijing & 0.89 & 1.04 & 0.66 & 0.82 & 1.82 & 0.78 & 1.08 & 1.32 & 1.96 & 0.91 & 1.67 & 0.82 \\
\hline Tianjin & 0.63 & 1.03 & 1.06 & 0.96 & 2.02 & 1.24 & 1.09 & 1.32 & 1.79 & 1.03 & 1.78 & 1.59 \\
\hline Hebei & 0.62 & 1.04 & 0.51 & 1.26 & 1.90 & 2.93 & 1.28 & 1.28 & 2.97 & 1.30 & 1.69 & 3.43 \\
\hline Shanxi & 1.02 & 1.05 & 0.93 & 1.21 & 1.94 & 7.72 & 1.49 & 1.27 & 3.88 & 1.26 & 1.71 & 9.09 \\
\hline Inner Mongolia & 1.32 & 1.05 & 1.24 & 1.23 & 1.83 & 4.25 & 1.42 & 1.27 & 3.04 & 1.36 & 1.62 & 5.28 \\
\hline Liaoning & 0.41 & 1.02 & 0.71 & 1.12 & 1.87 & 2.86 & 1.26 & 1.30 & 3.55 & 1.19 & 1.67 & 3.44 \\
\hline Jilin & 0.17 & 1.04 & 0.56 & 1.16 & 1.86 & 1.84 & 1.52 & 1.26 & 2.58 & 1.24 & 1.66 & 2.37 \\
\hline Heilongjiang & 0.95 & 1.04 & 1.01 & 1.16 & 1.91 & 2.32 & 1.85 & 1.24 & 3.48 & 1.21 & 1.70 & 2.86 \\
\hline Shanghai & 0.47 & 1.01 & 1.13 & 0.92 & 2.00 & 1.37 & 1.16 & 1.31 & 2.65 & 1.01 & 1.74 & 1.48 \\
\hline Jiangsu & 0.44 & 1.03 & 0.68 & 1.14 & 1.93 & 1.35 & 1.09 & 1.31 & 1.26 & 1.18 & 1.70 & 1.62 \\
\hline Zhejiang & 0.43 & 1.01 & 0.94 & 1.10 & 1.72 & 1.26 & 1.11 & 1.31 & 1.65 & 1.12 & 1.56 & 1.52 \\
\hline Anhui & 0.52 & 1.03 & 0.48 & 1.23 & 1.90 & 1.84 & 1.14 & 1.31 & 3.37 & 1.25 & 1.70 & 2.47 \\
\hline Fujian & 0.48 & 1.03 & 0.48 & 1.06 & 1.49 & 1.40 & 1.16 & 1.30 & 1.68 & 1.11 & 1.37 & 1.76 \\
\hline Jiangxi & 0.43 & 1.03 & 0.47 & 1.21 & 1.82 & 1.40 & 1.19 & 1.30 & 2.81 & 1.23 & 1.63 & 1.94 \\
\hline Shandong & 0.42 & 1.03 & 0.53 & 0.29 & 1.93 & 1.40 & 1.15 & 1.30 & 2.13 & 1.21 & 1.72 & 1.82 \\
\hline Henan & 0.37 & 1.03 & 0.46 & 1.17 & 1.94 & 1.43 & 1.15 & 1.31 & 2.72 & 1.20 & 1.72 & 1.98 \\
\hline Hubei & 0.79 & 1.04 & 0.48 & 1.19 & 1.37 & 1.64 & 1.29 & 1.29 & 3.51 & 1.18 & 1.33 & 2.20 \\
\hline Hunan & 1.46 & 1.06 & 0.49 & 1.20 & 1.67 & 1.33 & 1.42 & 1.27 & 2.89 & 1.21 & 1.55 & 1.74 \\
\hline Guangdong & 0.49 & 1.03 & 0.50 & 1.06 & 1.70 & 1.04 & 1.17 & 1.30 & 2.08 & 1.08 & 1.56 & 1.34 \\
\hline Guangxi & 0.33 & 1.02 & 0.55 & 1.22 & 1.49 & 1.80 & 1.23 & 1.30 & 2.69 & 1.23 & 1.38 & 2.20 \\
\hline Hainan & 0.23 & 1.00 & 0.95 & 0.06 & 1.64 & 2.97 & 1.19 & 1.30 & 3.01 & 1.01 & 1.52 & 2.22 \\
\hline Chongqing & 0.86 & 1.05 & 0.36 & 1.16 & 1.74 & 1.05 & 1.06 & 1.32 & 3.71 & 1.12 & 1.60 & 1.68 \\
\hline Sichuan & 0.33 & 1.02 & 0.61 & 1.08 & 1.05 & 2.10 & 1.06 & 1.32 & 3.98 & 1.07 & 1.06 & 2.80 \\
\hline Guizhou & 1.13 & 1.05 & 0.75 & 1.27 & 1.47 & 3.72 & 2.15 & 1.24 & 5.62 & 1.30 & 1.43 & 4.54 \\
\hline Yunnan & 1.17 & 1.05 & 0.47 & 1.21 & 0.86 & 3.56 & 1.42 & 1.28 & 3.57 & 1.23 & 0.88 & 4.06 \\
\hline Shaanxi & 0.45 & 1.03 & 0.46 & 1.14 & 1.93 & 2.53 & 1.15 & 1.30 & 2.76 & 1.16 & 1.71 & 3.23 \\
\hline Gansu & 0.71 & 1.04 & 0.53 & 1.21 & 1.49 & 3.63 & 1.29 & 1.29 & 4.67 & 1.22 & 1.39 & 4.27 \\
\hline Qinghai & 0.46 & 1.03 & 0.53 & 1.01 & 1.17 & 4.08 & 1.16 & 1.31 & 7.62 & 1.04 & 1.14 & 5.83 \\
\hline Ningxia & 0.53 & 1.04 & 0.41 & 0.82 & 1.81 & 8.71 & 1.16 & 1.31 & 3.28 & 1.44 & 1.60 & 9.64 \\
\hline Xinjiang & 0.82 & 1.04 & 0.72 & 1.15 & 1.79 & 6.45 & 1.28 & 1.30 & 6.76 & 1.22 & 1.60 & 7.25 \\
\hline
\end{tabular}

was higher than that of benchmark. In these provinces, coal consumption accounted for more than $60 \%$ of the energy consumption in primary industry. Increasing oil and gas consumption may significantly reduce their CI of the primary industry. Besides, the energy consumption structure effect of all provinces is higher than the benchmark, and there is no obvious spatial difference among these provinces.

In secondary industry, energy intensity effect is the leading driver for inter-provincial differences of CI. The energy intensity effect of most provinces is higher than the benchmark except Beijing. This indicates that the energy intensity of secondary industry in Beijing is lower than that of the benchmark. As a developed province, Beijing is committed to alleviating non-capital functions, vigorously develop high-tech industries, and eliminate low-value-added energyintensive industries. On the contrary, the energy intensity effect of Shanxi, Ningxia, and Xinjiang is much higher than that of other provinces. Traditional energy-intensive industries have always been pillar industries in Shanxi province, and the economic development of Shanxi is heavily dependent on fossil energy consumption (You et al. 2021). Due to the weak industrial base, the manufacturing industry in Ningxia and Xinjiang developed slowly and their energy efficiency was relative low. Therefore, Shanxi, Ningxia, and Xinjiang have great potential for CEs reduction, and promoting industrial upgrading and technological progress is a valid method to decrease their CI. The energy consumption structure effect of most provinces is higher than the benchmark except Yunnan. This is mainly due to the development of hydropower in Yunnan, and its non-fossil energy consumption accounts for much higher proportions than other provinces.

In tertiary industry, the spatial differences mainly derive from energy intensity effect. The energy intensity effects of all provinces are higher than the benchmark, especially Guizhou, Qinghai, and Xinjiang. In these provinces, tourism 
takes a high proportion of the tertiary industry. However, tourism industry in these provinces is still in a stage of rapid development, and their energy efficiency is relatively low. It is critical to integrating tourism resources and vigorously developing eco-tourism to reduce CEs (Wang et al. 2016). On the contrary, the CI of tertiary industry in the developed provinces such as Beijing, Tianjin, Jiangsu, Zhejiang, and Fujian was relatively low compared to other provinces. This is mainly due to the relatively high consumer demand and the relatively mature development of the service industry in these provinces. The spatial differences of fossil energy structure effect and energy consumption structure effect are similar. All provinces have great potential in optimizing the energy structure. Vigorously developing non-fossil energy sources take a crucial position in decraesing CI.

In general, the GDP of the secondary industry accounts for less than $50 \%$, but related CEs occupy more than $80 \%$ of the national total. Therefore, evolution of CI is mainly affected by the secondary industry. Reducing energy intensity is the most valid method to reduce CEs in all provinces except Beijing. For the secondary industry, there are two major ways to improve energy intensity. The first is to promote technological progress and improve energy efficiency. The second is to optimize the industrial structure and develop modern manufacturing. For provinces dominated by traditional manufacturing, such as Hebei, Jilin, and Liaoning, improving energy efficiency is the most valid method to reduce the CI of secondary industry. For provinces dominated by modern manufacturing such as Tianjin and Jiangsu, improving technological innovation capabilities and developing high-tech industries are of great significance to achieving CEs reduction goals. For Beijing, improving the energy structure and increasing non-fossil energy consumption are the most active method to decrease CEs. The development of clean energy power generation in accordance with local conditions and improving the long-distance transmission capacity of the power grid are essential to promote non-fossil energy consumption.

\section{Discussion}

During 1997-2017, the impact of energy intensity on CEs showed obvious temporal characteristics. Its inhibitory effect on the growth of CEs decreased significantly during 2000-2007. Many scholars thought that this is the negative impact of rapid economic growth (Zhang et al. 2018). Decomposition results show that the decline of energy intensity of the secondary industry in this period was much lower than that of the primary and tertiary industries, indicating that the low-carbonization process of the secondary industry in China was suppressed from 2002 to 2007. With the implementation of the "12th 5-Year" and "13th 5-Year" industrial transformation policies, the energy intensity of the secondary industry has continued to decline after 2012. Therefore, this paper thinks that in addition to technological progress, industrial structural improvement is also an effective means to promote energy intensity reduction. This will still play a positive role in curbing the growth of CEs. In addition, the impact of fossil energy structure and energy consumption structure on CEs is very limited. It indicates that the effects of clean energy policies such as coal-to-gas and renewable energy have not appeared. This is mainly due to the relatively low proportion and slow growth rate of clean energy. With the continuous growth of clean energy, its inhibitory effect on the growth of CEs will continue to appear.

The results of the scenario analysis show that China will not be able to achieve the 2030 carbon emission reduction target in the CPS, which is different from some previous studies (Zhang et al. 2020). This is mainly due to that the CPS in this study only considered existing energy and environmental policies. The long-term emission reduction goals which do not have specific policies were only considered in NPS and SDS. This result shows that although the Chinese government has put forward a series of emission reduction targets, these targets are still in the stage of recognition and have not been transitioned into specific action plans. And these targets cannot be achieved by existing energy and environmental policies. From decomposition results of predicted CEs, the development of non-fossil energy is the key to China's carbon emission reduction goals. However, from the results of NPS, it could be found that existing targets mainly put forward strong requirements for the decline of energy intensity. Although this can curb the growth of CEs in the short term, it can be seen from SDS that the impact of energy intensity on CEs will gradually decline due to diminishing marginal benefits. In SDS, affected by SDGs, the proportion of non-fossil energy sources increased, and CEs decreased significantly. Therefore, the Chinese government should promulgate strict non-fossil energy targets and formulate corresponding policies to ensure the stable replacement of fossil energy by non-fossil energy.

\section{Policy recommendations}

Based on the above analysis, some potential measures should be implemented to control China's CEs growth. The results of CPS indicate that current policies cannot curb the growth of CEs in China. The Chinese government should transform the binding targets into concrete policies, and adopt strong measures especially in the secondary industry. Compared with NPS, reducing energy intensity is an effective means to curb the growth of CEs in the short term. Especially in Ningxia, Xinjiang, and Inner Mongolia, these provinces have relatively large-scale 
energy-intensive industries such as coal chemical industry and thermal power generation. These provinces did not achieve the CI reduction target during the 12th 5-Year Plan period. Therefore, more restrictive policies should be implemented, including eliminating outdated production capacity and promoting the recovery and reuse of energy. In addition, the CEs of Shandong, Jiangsu, and Heilongjiang was significantly higher than other provinces, reducing their CEs is crucial for achieving China's carbon emission reduction targets. In these provinces, thermal power generation accounts for more than $40 \%$ of CEs. Therefore, Compared with NPS, improving power generation efficiency can effectively reduce their CEs.

Optimizing the energy structure and promoting nonfossil energy consumption are fundamental measures to ensure the achievement of CEs emission reduction targets. Comparing NPS and SDS, the contribution of energy efficiency improvement to the decline of China's CEs has some limitations. Optimizing the energy structure is the key to promoting the continued decline of China's CEs, especially in the secondary industry. However, compared with technological progress, energy transition policy is more complex and more limited by resource endowments. Therefore, it is necessary to formulate clean energy policies based on local conditions to effectively promote the continuous decline of CEs. From the decomposition results, Shanxi, Inner Mongolia, Shandong, Ningxia, and other provinces account for a relatively high proportion of coal consumption, and extending the more powerful "coalto-gas" policy to these provinces can significantly promote the decline of their CEs. In addition, Hubei, Chongqing, and Yunnan are rich in renewable energy resources. Constructing renewable energy power generation projects and promoting the replacement of fossil energy by renewable energy can effectively reduce their CEs.

The development of low-carbon infrastructure and the overall planning of power grids are important guarantees for China's energy transition. Comparing CPS and NPS, the impact of the energy transition on the decline of China's CEs is limited. This is mainly due to the slow development of non-fossil energy. In SDS, the growth of nonfossil energy has significantly contributed to the decline of China's CEs, but this requires effective policies support. As mentioned above, most provinces in China do not have the innate conditions for the development of renewable energy. Therefore, it is a more realistic choice to develop renewable energy in accordance with local conditions and to equip long-distance power transmission networks. This will not only realize the long-distance transmission of clean energy, but also increase China's demand for clean energy and promote the development of renewable energy in Yunnan, Hubei, Chongqing, and other provinces.

\section{Conclusions}

This study first analyzed the evolution trend and influencing factors of China's CEs during 1997-2017. Then, scenario analysis was applied to analyze China's CEs and CI at industrial level from 2017 to 2040 in different scenarios. Next, the LMDI model was used to explore the driving force of China's CEs reduction in different scenarios. Furthermore, this paper analyzed the differences in CEs and $\mathrm{CI}$ of various provinces from the provincial level. Finally, the ST-LMDI model was used to explore the CEs reduction potential and potential paths at provincial level based on SDS. The main conclusions are as follows.

During 1997-2017, China's CEs growth was continuous, with an average annual growth rate of $6.26 \%$. Secondary industry was the main source of CEs, accounting for more than $80 \%$ of national total. Activity effect was the dominant force for CEs growth. Benefiting from technological progress, energy intensity was a key driver in restraining the growth of CEs. However due to extensive economic development, the restraining effect was not obvious during 2002-2007. Population effect was a key factor for CEs growth in tertiary industry especially during 2012-2017 (25.68\%). With the development of non-fossil energy, the energy consumption structure effect began to curb the CEs growth $(-2.23 \%)$ during 2007-2012, and continued to show restraint effect $(-1.40 \%)$ during 2012-2017. Therefore, this paper believes that in addition to technological progress, industrial structural improvement is also an effective means to promote energy intensity reduction. This will still play a positive role in curbing the growth of CEs. In addition, the impact of fossil energy structure and energy consumption structure on CEs is very limited. It indicates that the effects of clean energy policies such as coal-to-gas and renewable energy have not appeared. This is mainly due to the relatively low proportion and slow growth rate of clean energy. With the continuous growth of clean energy, its inhibitory effect on the growth of CEs will continue to appear.

In the scenario analysis, different energy and environmental policies have had a clear influence on CEs. China will not be able to achieve the 2030 carbon emission reduction target in the CPS, which means that although the Chinese government has put forward a series of emission reduction targets, these targets are still in the stage of recognition and have not been transitioned into specific action plans. And these targets cannot be achieved by existing energy and environmental policies. In NPS, China's CEs will peak at 2030 due to the improvement of energy efficiency and optimization of energy structure. In addition, China's CI will drop by $60 \%$ in 2030 compared to 2005 , which means that China will achieve the lower 
limit of 2030 CEs reduction target. It is dominantly caused by the decrease in CEs from secondary industry. In SDS, CEs continue to decline from 2017 to 2040 . CI will drop by $72.46 \%$ compared to 2005 . This scenario is far better than the other two scenarios in terms of CEs reduction. However, the contribution of the energy transition to the decline of CEs mainly occurred in SDS, which means that the Chinese government should promulgate strict non-fossil energy targets and formulate corresponding policies to ensure the stable replacement of fossil energy by nonfossil energy.

For most provinces, improving energy efficiency is an effective means to reduce CEs. Especially in Ningxia, Xinjiang, and Inner Mongolia, more restrictive policies should be implemented, including eliminating outdated production capacity and promoting the recovery and reuse of energy. The CEs of Shandong, Jiangsu, and Heilongjiang was significantly higher than other provinces. In these provinces, thermal power generation accounts for more than $40 \%$ of CEs. Improving power generation efficiency can effectively reduce their CEs. Optimizing the energy structure and promoting non-fossil energy consumption are fundamental measures to ensure the achievement of CEs emission reduction targets. Especially for the provinces rich in renewable energy including Hubei, Chongqing, and Yunnan. Constructing renewable energy power generation projects and promoting the replacement of fossil energy by renewable energy can effectively reduce its CEs.

Supplementary Information The online version contains supplementary material available at https://doi.org/10.1007/s10098-021-02240-7.

Acknowledgements We thank the reviewers for their valuable comments and suggestions.

Authors' contributions CS did the scenario and decomposition analysis, and was a major contributor in writing the manuscript. TZ came up with this research idea and financially supported this work. JW analyzed existing literatures and provided a lot of work for the revision of the paper. All authors read and approved the final manuscript.

Funding This work was funded by the Major Program of Social Science Foundation of Tianjin Municipal Education Commission (No. 2016JWZD04) and the Ministry of Education of Humanities and Social Science Research Fund Plan (No. 15YJA790091).

Data availability The datasets generated and analyzed during the current study are available in the National Bureau of Statistics of China, China Energy Statistics Yearbook, and China Electricity Statistical Yearbook. http://www.stats.gov.cn/tjsj/ndsj/

\section{Declarations}

Conflict of interest The authors declare that they have no conflict of interest.

\section{References}

Bing X, Mitchell B, Yong G, Ren W, Mueller K, Ma Z, Oliveira J, Fujita T, Tobias M (2014) A review on China's pollutant emissions reduction assessment. Ecol Ind 38:272-278

Cui C, Wang Z, Cai BF, Peng S, Wang Y, Xu CD (2021) Evolutionbased $\mathrm{CO} 2$ emission baseline scenarios of Chinese cities in 2025. Appl Energy 281:116116

Deng MJ, Zhong SH, Xiang GC (2019) Carbon emission reduction effect of China's final demand structure change from 2013 to 2020: a scenario-based analysis. Carbon Manage 10:387-404

Ding ST, Zhang M, Song Y (2019) Exploring China's carbon emissions peak for different carbon tax scenarios. Energy Policy 129:1245-1252

Dong H, Dai H, Dong L, Fujita T, Geng Y, Klimont Z, Inoue T, Bunya S, Fujii M, Masui T (2015) Pursuing air pollutant co-benefits of $\mathrm{CO} 2$ mitigation in China: a provincial leveled analysis. Appl Energy 144:165-174

Du K, Lin B (2015) Understanding the rapid growth of China's energy consumption: a comprehensive decomposition framework. Energy 90:570-577

Fatima T, Shahzad U, Cui L (2021) Renewable and nonrenewable energy consumption, trade and $\mathrm{CO} 2$ emissions in high emitter countries: does the income level matter? J Environ Plan Manage 64:1227-1251

Ghazouani A, Jebli MB, Shahzad U (2021) Impacts of environmental taxes and technologies on greenhouse gas emissions: contextual evidence from leading emitter European countries. Environ Sci Pollut Res 28:22758-22767

Guo J, Zhou Y, Ali S, Shahzad U, Cui L (2021) Exploring the role of green innovation and investment in energy for environmental quality: an empirical appraisal from provincial data of China. $\mathbf{J}$ Environ Manage 292:112779

He K, Lei Y, Pan X, Zhang Y, Zhang Q, Chen D (2010) Co-benefits from energy policies in China. Energy 35:4265-4272

IEA (2018) World energy outlook 2018. International Energy Agency

Ikram M, Xia W, Fareed Z, Shahzad U, Rafique MZ (2021) Exploring the nexus between economic complexity, economic growth and ecological footprint: contextual evidences from Japan. Sustain Energy Techn 47:101460

IPCC (2006) Greenhouse gas inventory: IPCC guidelines for national greenhouse gas inventories. United Kingdom Meteorological Office, England

Jiang JJ, Ye B, Xie DJ, Tang J (2017) Provincial-level carbon emission drivers and emission reduction strategies in China: combining multi-layer LMDI decomposition with hierarchical clustering. J Clean Prod 169:178-190

Jiang KJ, He CM, Dai HC, Liu J, Xu XY (2018) Emission scenario analysis for China under the global $1.5^{\circ} \mathrm{C}$ target. Carbon Manage 9:481-491

Li A, Zhang A, Zhou Y, Yao X (2017a) Decomposition analysis of factors affecting carbon dioxide emissions across provinces in China. J Clean Prod 141:1428-1444

Li H, Zhao YH, Qiao XY, Liu Y, Cao Y, Li Y, Wang S, Zhang ZH, Zhang YF, Weng JF (2017b) Identifying the driving forces of national and regional $\mathrm{CO} 2$ emissions in China: based on temporal and spatial decomposition analysis models. Energy Econ 68:522-538

Lin BQ, Liu WS (2017) Scenario prediction of energy consumption and CO2 emissions in China's machinery industry. Sustainability 9:87

Liu F, Klimont Z, Zhang Q, Cofala J, Zhao L, Huo H, Nguyen B, Schöpp W, Sander R, Zheng B, Hong C, He K, Amann M, Heyes C (2013) Integrating mitigation of air pollutants and greenhouse gases in Chinese cities: development of GAINS-City model for Beijing. J Clean Prod 58:25-33 
Liu N, Ma Z, Kang J, Su B (2019) A multi-region multi-sector decomposition and attribution analysis of aggregate carbon intensity in China from 2000 to 2015. Energy Policy 129:410-421

Liu Q, Zheng XQ, Zhao XC, Chen Y, Lugovoy O (2018) Carbon emission scenarios of China's power sector: impact of controlling measures and carbon pricing mechanism. Adv Clim Chang Res 9:27-33

Malik A, Lafortune G, Carter S, Li M, Lenzen M, Kroll C (2021) International spillover effects in the EU's textile supply chains: a global SDG assessment. J Environ Manage 295:113037

Mao X, Yang S, Liu Q, Tu J, Jaccard M (2012) Achieving CO2 emission reduction and the co-benefits of local air pollution abatement in the transportation sector of China. Environ Sci Policy 21:1-13

NBSC (1998-2018a) Chinese statistics yearbook. National Bureau of Statistics of China, Beijing

NBSC (1998-2018b) Chinese energy statistics yearbook. National Bureau of Statistics of China, Beijing

NBSC (1998-2018c) China electricity statistical yearbook. National Bureau of Statistics of China, Beijing

NDRC (2017) Thirteenth 5-year plan for the construction of watersaving society. National Development and Reform Commission

NDRC (2021) The 14th 5-Year plan for energy development. In: commission NDaR (Hrsg.). National Development and Reform Commission

Niu DX, Wang KK, Wu J, Sun LJ, Liang Y, Xu XM, Yang XL (2020) Can China achieve its 2030 carbon emissions commitment? Scenario analysis based on an improved general regression neural network. J Clean Prod 243:118558

OECD (2019) Long-term baseline projections, no. 103. OECD Economic Outlook: Statistics and Projections. https://doi.org/10.1787/ 68465614-en

Qiao H, Chen S, Dong X, Dong K (2019) Has China's coal consumption actually reached its peak? National and regional analysis considering cross-sectional dependence and heterogeneity. Energy Econ 84:104509

Qin JC, Tao H, Zhan MJ, Munir Q, Brindha K, Mu GJ (2019) Scenario Analysis of carbon emissions in the energy base, Xinjiang autonomous region, China. Sustainability 11:1-18

Rafaj P, Schpp W, Russ P, Heyes C, Amann M (2013) Co-benefits of post-2012 global climate mitigation policies. Mitig Adapt Strat Glob Change 18:801-824

Shahzad U, Radulescu M, Rahim S, Isik C, Yousaf Z, Ionescu SA (2021) Do environment-related policy instruments and technologies facilitate renewable energy generation? Exploring the contextual evidence from developed economies. Energies 14:690

Sharma GD, Shah MI, Shahzad U, Jain M, Chopra R (2021) Exploring the nexus between agriculture and greenhouse gas emissions in BIMSTEC region: the role of renewable energy and human capital as moderators. J Environ Manage 297:113316

Shrestha RM, Pradhan S (2010) Co-benefits of CO2 emission reduction in a developing country. Energy Policy 38:2586-2597

Song Y, Sun JJ, Zhang M (2021) Research on evolution in the center of gravity and a contribution decomposition of energy-related $\mathrm{CO} 2$ emissions at the provincial level in China. Emerg Mark Financ $\operatorname{Tr}$ 57:684-697

Sun ZR, Liu YD, Yu YN (2019) China's carbon emission peak pre2030: Exploring multi-scenario optimal low-carbon behaviors for China's regions. J Clean Prod 231:963-979

Takeshita T (2012) Assessing the co-benefits of CO2 mitigation on air pollutants emissions from road vehicles. Appl Energy 97:225-237

Tian H, Qiu P, Ke C, Gao J, Long L, Liu K, Liu X (2013) Current status and future trends of SO2 and NOx pollution during the 12th FYP period in Guiyang city of China. Atmos Environ 69:273-280

UN (2015) Transforming our world: the 2030 agenda for sustainable development, https://sustainabledevelopment.un.org/post2015/ transformingourworld
UN (2018) World population prospects:2018. United Nation, https:// population.un.org/wup/Publications/

Wang H, Zhou P (2018) Multi-country comparisons of CO2 emission intensity: the production-theoretical decomposition analysis approach. Energy Econ 74:310-320

Wang J, Yang HZ, Lu ZB (2010) Energy demand outlook and scenario analysis of carbon dioxide emission of China. 2010 the second China energy scientist forum 1: pp. 1280-1286

Wang M, Feng C (2017) Decomposition of energy-related CO2 emissions in China: an empirical analysis based on provincial panel data of three sectors. Appl Energy 190:772-787

Wang Q, Wang S (2020) Preventing carbon emission retaliatory rebound post-COVID-19 requires expanding free trade and improving energy efficiency. Sci Total Environ 746:141158

Wang Q, Han X (2021) Is decoupling embodied carbon emissions from economic output in Sino-US trade possible? Technol Forecast Soc Change 169:120805

Wang Q, Wang S, Jiang X (2021a) Preventing a rebound in carbon intensity post-COVID-19: lessons learned from the change in carbon intensity before and after the 2008 financial crisis. Sustain Prod Consum 27:1841-1856

Wang Q, Zhang F (2021) What does the China's economic recovery after COVID-19 pandemic mean for the economic growth and energy consumption of other countries? J Clean Prod 295:126265

Wang S, Fang C, Wang Y (2016) Spatiotemporal variations of energyrelated $\mathrm{CO} 2$ emissions in China and its influencing factors: an empirical analysis based on provincial panel data. Renew Sust Energ Rev 55:505-515

Wang SJ, Wang JY, Li SJ, Fang CL, Feng KS (2019) Socioeconomic driving forces and scenario simulation of $\mathrm{CO} 2$ emissions for a fast-developing region in China. J Clean Prod 216:217-229

Wang WY, Wang J, Guo F (2018a) Carbon Dioxide (CO2) Emission reduction potential in east and south coastal China: scenario analysis based on STIRPAT. Sustainability 10:1836

Wang Y, Zhou Y, Zhu L, Zhang F, Zhang Y (2018b) Influencing factors and decoupling elasticity of China's transportation carbon emissions. Energies 11:1157

Wang Z, BenJebli M, Madaleno M, Doğan B, Shahzad U (2021b) Does export product quality and renewable energy induce carbon dioxide emissions: Evidence from leading complex and renewable energy economies. Renew Energy 171:360-370

Wen L, Liu YJ (2016) The peak value of carbon emissions in the Beijing-Tianjin-Hebei region based on the STIRPAT model and scenario design. Pol J Environ Stud 25:823-834

Xu SC, He ZX, Long RY (2014) Factors that influence carbon emissions due to energy consumption in China: decomposition analysis using LMDI. Appl Energy 127:182-193

You ZW, Zhao T, Song C, Wang J (2021) Analyzing China's coalrelated carbon emissions from economic growth perspective: through decoupling and decomposition model. Environ Sci Pollut Res 28:3703-3718

Yu M, Liu FY, Shu MD, Liu JP, Chen C (2019) Quantitative analysis and scenario prediction of energy consumption carbon emissions in urban agglomerations in China: case of Beijing-Tianjin-Hebei region. Third Int Conf Energy Eng Environ Prot 227:062042

Yuan R, Rodrigues J, Tukker A, Behrens P (2018) The impact of the expansion in non-fossil electricity infrastructure on China's carbon emissions. Appl Energy 228:1994-2008

Zhang C, Su B, Zhou KL, Yang SL (2019) Decomposition analysis of China's CO2 emissions (2000-2016) and scenario analysis of its carbon intensity targets in 2020 and 2030. Sci Total Environ 668:432-442

Zhang M, Bai C, Zhou M (2018) Decomposition analysis for assessing the progress in decoupling relationship between coal consumption and economic growth in China. Resour Conserv Recycl 129:454-462 
Zhang PY, He JJ, Hong X, Zhang W, Qin CZ, Pang B, Li YY, Liu Y (2017) Regional-level carbon emissions modelling and scenario analysis: a STIRPAT case study in Henan Province China. Sustainability 9:2342

Zhang SC, Zhao T (2019) Identifying major influencing factors of $\mathrm{CO} 2$ emissions in China: regional disparities analysis based on STIRPAT model from 1996 to 2015. Atmos Environ 207:136-147

Zhang X, Geng Y, Shao S, Dong HJ, Wu R, Yao TL, Song JK (2020) How to achieve China's $\mathrm{CO} 2$ emission reduction targets by provincial efforts?: an analysis based on generalized Divisia index and dynamic scenario simulation. Renew Sust Energ Rev 127:109892
Zhu CZ, Wang M, Du WB (2020) Prediction on peak values of carbon dioxide emissions from the Chinese transportation industry based on the SVR model and scenario analysis. J Adv Transp 2020:8848149

Publisher's Note Springer Nature remains neutral with regard to jurisdictional claims in published maps and institutional affiliations. 